Research Article

\title{
Investigation of the Optimal Layout of the Roadway in Closely Spaced Ultra-Thick Coal Seams Mining with Remaining Coal Pillars
}

\author{
Bin Zhao $\mathbb{D}^{\mathbb{D}},{ }^{1,2}$ Le Gao $\mathbb{D}^{\mathrm{D}},{ }^{3}$ Xianghui Tian $\mathbb{D}^{3},{ }^{3}$ and Yingyu Sun $\mathbb{i D}^{3}$ \\ ${ }^{1}$ School of Safety Engineering, China University of Mining and Technology, Xuzhou 221116, China \\ ${ }^{2}$ China Coal Datong Energy Co., Ltd., Datong 037038, China \\ ${ }^{3}$ School of Civil and Resource Engineering, University of Science and Technology Beijing, Beijing 100083, China
}

Correspondence should be addressed to Bin Zhao; zhaobin_tashan@163.com

Received 20 August 2021; Revised 15 October 2021; Accepted 2 November 2021; Published 24 November 2021

Academic Editor: Fan Deyuan

Copyright (c) 2021 Bin Zhao et al. This is an open access article distributed under the Creative Commons Attribution License, which permits unrestricted use, distribution, and reproduction in any medium, provided the original work is properly cited.

The reasonable layout of the roadway in closely spaced, ultra-thick coal seam mining is of great significance to mining safety. Based on the research background of repeated roof leaks in the process of repairing the return air roadway in working face No. 30503 in the Tashan Coal Mine, theoretical analysis, in situ engineering testing, and numerical simulation were jointly adopted to evaluate the stability of the return air roadway under two schemes of repairing the original return air roadway and excavating a new return air roadway. The results show that the vertical mining-induced fissure above the roadway will cause severe damage to the roadway due to the influence of working-face mining when restoration of the roadway excavation is adopted. When choosing to excavate a new return air roadway, the new return air roadway just staggers the vertical cracks located in the top slab of the original return air roadway, putting the roadway in a state of stress reduction, making the roadway itself more stable and conducive to support. Therefore, the new air return tunnel was selected to establish the working face. To ensure safety of the working face during the mining of the original return air roadway, the original return air roadway was filled with high water content materials. Site investigation data show that this material plays a cushioning role in the filling section of the original return air roadway during the mining of the 30503 working face, and the deformation of the new return air roadway during the filling section crossing the original return roadway is stable and well controlled.

\section{Introduction}

Closely spaced coal seams are widely distributed across China, such as those in the Datong mining area, Xishan mining area, and Xinwen mining area [1-4]. The roadway layout and control techniques used in lower coal seam in the mining of such seams have always been a focus of much research, both at home and abroad. Compared with mining in a single coal seam, a closely spaced coal seam is more severely affected by the mining of the upper seam and the mining of the adjacent working face, which results in a very complicated spatial structure of, and stress environment in, the rock surrounding the roadway. The roadway dynamic pressure is significant and more prone to roof leakage and other accidents in the process of roadway excavation and working surface recovery [5-10].
Regarding the roadway layout in extra-thick coal seams, scholars have conducted much research [11-13]. Aiming at the problem of the lack of coal pillar retention theory between roadways, Yang and Gou [13] studied the mechanical behavior of the coal pillars in double roadways with the coal pillars between roadways as the engineering context and calculated the width of the coal pillar plastic zone according to the SMP criterion. The distribution characteristics of surrounding rock stress and plastic zone during primary and secondary disturbances of coal pillars between roadways were discussed. Wang, $\mathrm{Ma}, \mathrm{Gao}$, and $\mathrm{He}$ et al. [14-17] evaluated the surrounding rock stress and plastic zone distribution under different roadway layouts by numerical simulation. He et al. [17] investigated the deformation and failure patterns in the surrounding rock under double- 
roadway heading face mining. They found that the low strength of rock around the roadway, poor mechanical properties, multiple recovery, and long-term high stress are the main reasons for the overall instability of the roadway: strengthening the integrity of the surrounding rock of the roadway and the key parts (coal pillar and roof) is key to the control of the surrounding rock. Yan, Song, Sun, Liu, Chen, Cheng, and Kong et al. [18-24] studied the stress field and plastic zone failure of the upper seam under the condition of multiple closely spaced coal seams and proposed that the roadway should be arranged in the stress reduction zone. Wang, Dong, Guo, He, and Hao, Tu, Qin, Liu, Zhao, Jiang et al. [25-34] determined the main factors influencing roadway deformation and failure during the recovery process and proposed that the roadway layout and surrounding rock control are effective measures with which to maintain the stability of the roadway. Guo et al. [27] established a mechanical model of high- and low-key blocks and proposed a combined support technique using narrow coal pillars in the roadway along the gob for a hard base roof aiming at the coal pillar width and surrounding rock control of roadway driving along gob in fully mechanized caving mining in Madaotou with its hard basic roof and extra-thick coal seam. To solve the problems of severe deformation and failure of the roadway in the lower coal seam under the influence of dynamic pressure during the closely spaced extra-thick coal seam mining in Sunjiagou, He et al. [28] ascertained the main factors influencing the roadway deformation and failure: the roadway was then optimized and the support and reinforcement measures were proposed. Zhao et al. [33] revealed the large deformation mechanisms acting in a deep, fractured roadway and proposed corresponding control techniques thereof by investigating the failure characteristics of the roadway and internal fracture characteristics of the surrounding rock. Jiang et al. [34] used a three-dimensional printed (3DP) sandstone model to characterize the overall failure process in double tunnels and proposed the safety factor method for the overall safety evaluation of multitunnel structures.

Many effective solutions have been proposed for the layout of mining roadways and control of the rock surrounding extra-thick coal seam, but most of them are specific to the mine at hand. It is rare to see the optimal layout of an extra-thick coal seam roadway layout under condition of closely spaced coal seams. In the present research, to ensure the safety of the working face in the process of recovery, the return air roadway of the 30503 working face of Tashan Coal Mine, which includes the aforementioned special mining conditions was taken as a background, and the layout and control measures of the return air roadway in these closely spaced, extra-thick coal seams were made by a combination of field measurement and numerical simulation.

\section{Engineering Background}

2.1. Working Face Overview. The 30503 working face in Tashan Coal Mine is worked by fully mechanized top coal caving when mining the $3-5 \#$ coal seam with an average coal thickness of $14 \mathrm{~m}$ and a distance of $4.6 \mathrm{~m}$ from the overlying 2\# coal seam. The overlying 10201 and 10203 working faces have been mined, leaving a $20 \mathrm{~m}$ coal pillar in the middle (Figure 1). The 30503 working face is on the east side of the 30501 gob, and the west side is solid coal. The initial design of 30501 working face adopts the 30501 original return air roadway (the repaired roadway). The horizontal distance between this roadway and the remaining coal pillar of 2\# coal seam is $15 \mathrm{~m}$. When the roadway is driven to $955 \mathrm{~m}$, the plan is changed and 30501 return air roadway is adopted. In the design of the 30503 working face, it is planned to reuse the original return air roadway of 30501 as the return air roadway. However, during the restoration of the original return air roadway to $955 \mathrm{~m}$, due to the damage to the original roadway structure, roof-falling is severe, which readily leads to roof leakage. The level of the roadway is adjusted to ensure the safety of roadway repair and driving; there is a large distance between the roadway floor and the original roadway roof so the original roadway has been partially filled with coal, and the roof of the roadway repair section is prone to caving.

\subsection{Roof Failure Characteristics of the Repaired Roadway.} The 30503 return air roadway was closed during mining at the 30501 working face. The roadway was severely damaged due to the influence of mining on the working face. The roof and the two sides were badly fractured and broken, with significant subsidence recorded; the roof and two sides of the net pocket appeared, part of the anchor and anchor cable anchorage failure occurred, resulting in the net pocket being pulled out; and the deformation of the roadway was then further aggravated, leading to the closure of the roadway. The roof drilling peep and deformation monitoring of deep and shallow base point methods were used to determine the degree of development of joints and cracks in the rock surrounding the 30503 repaired roadway roofs.

2.2.1. Roof Drilling Peep. Distances from the return air duct heading head of $10 \mathrm{~m}$ (peeping point 01), $40 \mathrm{~m}$ (peeping point 02 ), $70 \mathrm{~m}$ (peeping point 03 ), $100 \mathrm{~m}$ (peeping point 04), $130 \mathrm{~m}$ (peeping point 05 ), and a point some $10 \mathrm{~m}$ from the return air duct heading at the roadway section were selected for drilling peeping. Besides, measuring points were arranged every other meter on the roof of the roadway section, giving a total of seven points. The layout of measuring points on the roadway roof and section is shown in Figure 2.

The results of drilling peeps (Figure 3 ) show that the rock structure within the drilling range of the roadway roof is mainly that of the coal seam, with small amounts of kaolinite mudstone and carbonaceous mudstone interlayer present. The overall performance of drill hole fragmentation indicates that the coal in the shallow part of the roof is broken, cracks therein are well developed, and separations are found in many places, such as at depths of $1.5 \mathrm{~m}$ and $1.8 \mathrm{~m}$, but the shape of the drill hole has not changed significantly. With the increasing depth, the number of fractures in the hole gradually decreases, and the integrity of the hole wall is 


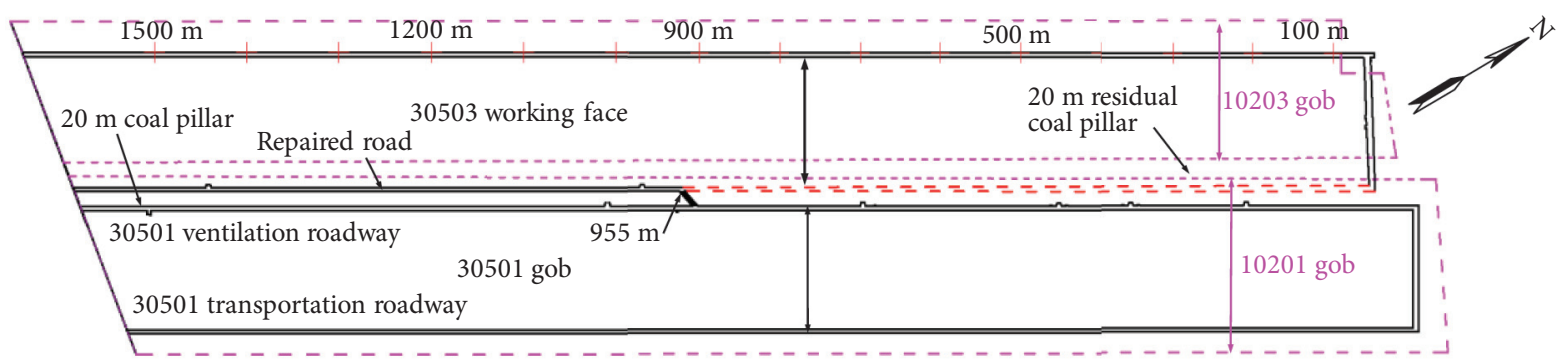

(a)

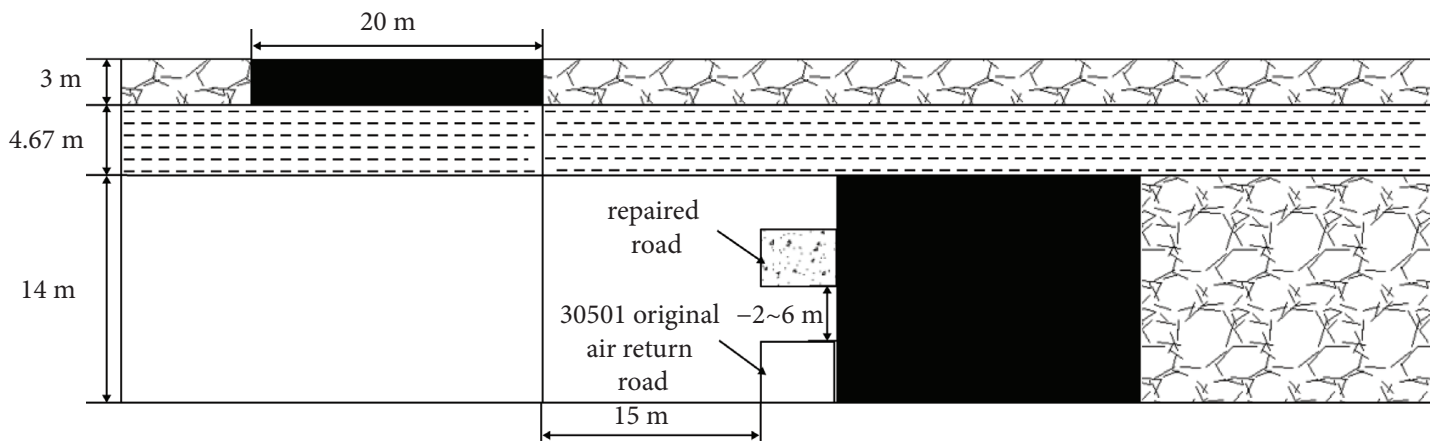

(b)

Figure 1: The layout of the 30503 working face. (a) Plan. (b) Elevation.

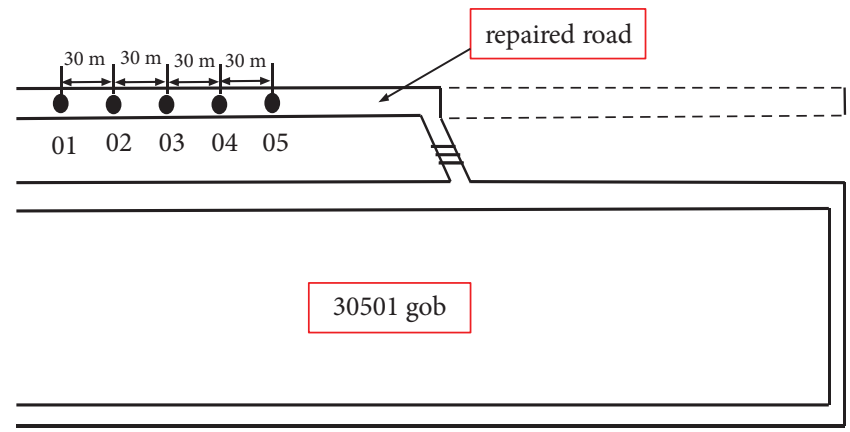

(a)

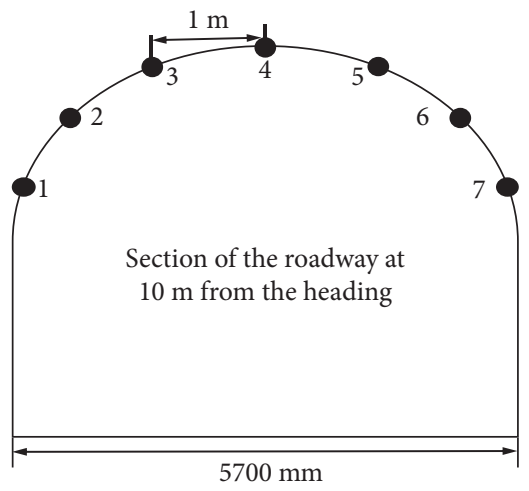

(b)

Figure 2: Layout of roadway roof measuring points. (a) Layout of roadway roof measuring points. (b) Layout of section measurement points.

gradually improved. However, there remain many cracks in the range of 5-6 $\mathrm{m}$ (mainly vertical cracks). Combined with the historical mining sequence and working face layout of the mine, it can be found that the distance between $2 \#$ and $3 \sim 5 \#$ coal seam is only $4.6 \mathrm{~m}$, and the top coal of 30503 working face has been broken due to the influences of the remaining coal pillar and the upper coal seam working face.

2.2.2. Analysis of Roof Deformation. A set of roof separation gauges were arranged at $25 \mathrm{~m}$ intervals on the roof of the 30503 repaired roadway. They were used for real-time monitoring and recording of rock displacement of the roof. The monitoring data of roof fall at $540 \mathrm{~m}$ and $640 \mathrm{~m}$ during roadway driving were analyzed.
From the roof subsidence monitoring data (Figure 4), the subsidence at points where roof falls occur is found to be similar. The maximum subsidence at the shallow base point of $2 \mathrm{~m}$ is in the range of $400-450 \mathrm{~mm}$, and the deep base point of $6 \mathrm{~m}$ is in the range of $200-300 \mathrm{~mm}$. The roof subsidence of two places exhibits a similar trend: within $0-100 \mathrm{~m}$ behind the heading, the roadway subsidence increases slowly, and the difference in deformation between the shallow and deep base points is small (within $50 \mathrm{~mm}$ ), indicating that the overall roof of the roadway within the range of $0 \sim 100 \mathrm{~m}$ starts sinking, and layer separation is small; from 100 to $300 \mathrm{~m}$, the roof sinks rapidly, and the gap between the deep and shallow base point deformation also increases. This shows that the surrounding rock within $2 \mathrm{~m}$ of the roof is relatively 


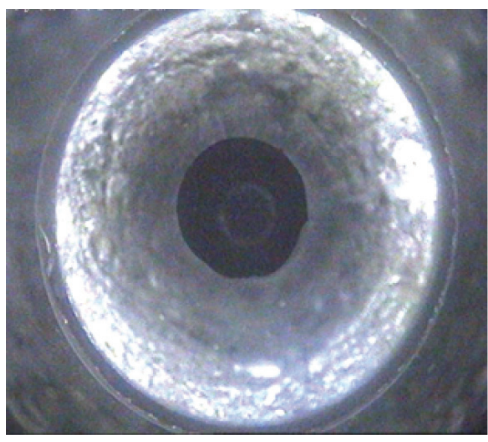

(a)

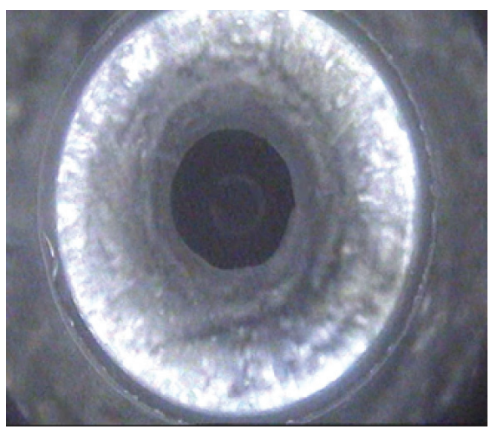

(d)

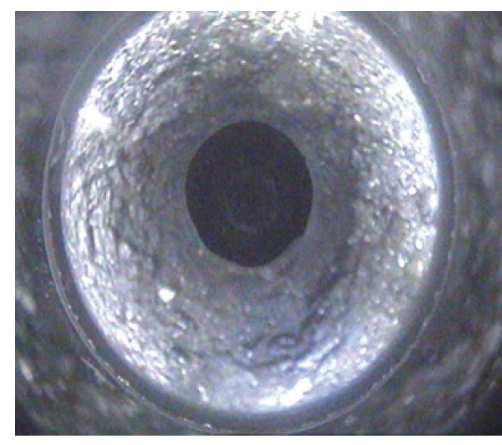

(b)

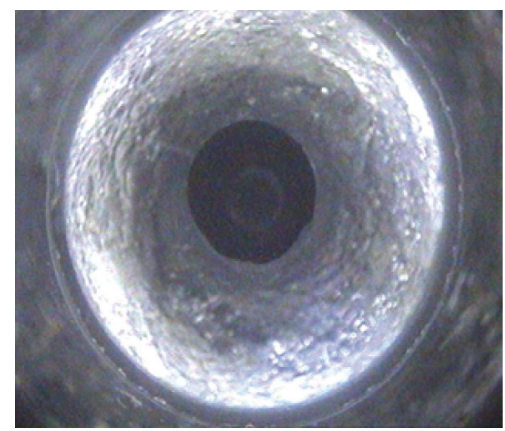

(e)

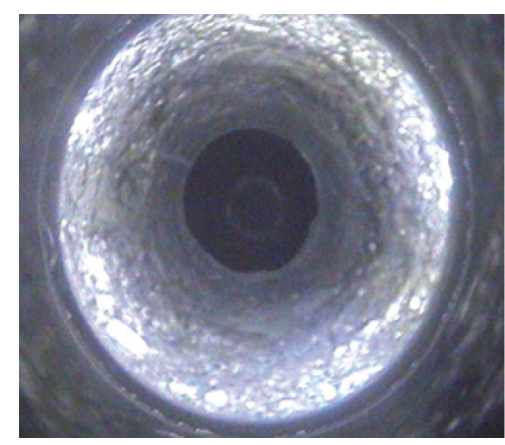

(c)

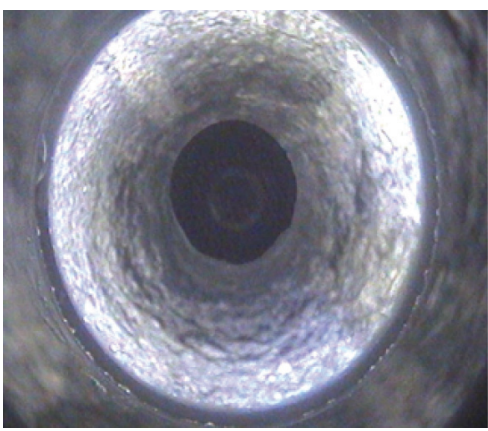

(f)

FiguRe 3: Drilling peep results of 30503 repaired roadway roof. (a) Cracks at $2.9 \mathrm{~m}$ in no. 01 borehole. (b) Cracks at $3.4 \mathrm{~m}$ in no. 02 borehole. (c) Cracks at $5.4 \mathrm{~m}$ in no. 03 borehole. (d) Cracks at $1.5 \mathrm{~m}$ in no. 04 borehole. (f) Cracks at $2.5 \mathrm{~m}$ in no. 04 borehole. (e) Cracks at $6.5 \mathrm{~m}$ in no. 05 borehole.

broken, and layer separation is increasing. When the layer separation in the roof of the roadway is too large, a roof fall will occur; beyond $300 \mathrm{~m}$, the deformation increases slowly, and the roof subsidence tends to stabilize. The causes of such large roadway deformation can be attributed thus: on the one hand, the thickness of the $3 \sim 5 \#$ coal seam is $14 \mathrm{~m}$, and the original air return roadway is $4 \mathrm{~m}$ high, so the roof subsidence to which we refer does not mean that of the overlying rock, but the subsidence of the coal overlying the seam. Due to the influence of the adjacent working face, the coal above the roadway is already in a broken state, so after the roadway is excavated, the roof coal seam of the roadway undergoes a greater deformation. On the other hand, the distance between 2\# coal seam and $3 \sim 5 \#$ coal seam is only $4.6 \mathrm{~m}$, which is affected by the overlying goaf. At this time, the roof of $3 \sim 5 \#$ coal seam must be affected. It can be calculated that, after the mining of \# 2 coal seam, the affected area of the floor has a length of about $13 \mathrm{~m}$, so the top coal of $3 \sim 5 \#$ is largely in a broken state.

Combined with the roof drilling and deformation monitoring results of the repaired roadway, it can be found that due to the close seam spacing and the mining of adjacent working faces, the surrounding rock in the repaired roadway roof has become broken. Therefore, after the roadway is driven, roof subsidence is characterized by rapid deformation, increasing layer separation, and a wide range of influence. So, if the return air roadway is continued to be driven forward, the roadway roof is likely to collapse again.
Therefore, considering the subsequent roadway driving and safe mining at the working face, designing a reasonable and effective roadway layout plan for the 30503 working face is a problem that needs to be solved urgently.

\section{Optimal Layout of the Return Air Roadway in the 30503 Working Face}

3.1. Optimized Roadway Layout. According to the mining geological conditions of the fully mechanized top coal caving face in the extra-thick coal seam of Tashan Coal Mine, the optimization problem of the roadway layout of the 30503 working face involves mainly the optimization of the return air roadway layout. As it is close to the gob of the 30501 working face, considering the influence of the concentrated coal pillar in the upper $2 \#$ coal seam, options for the layout of return air roadway include repairing the original return air roadway or driving the new return air roadway (in this case, the original return air roadway can either be filled or not).

3.1.1. Repair the Original Return Air Roadway. This plan is based on the 30501 original return air roadway that has been repaired so far, maintaining the original roadway layout and continuing to move forward. The roadway layout is shown in Figure 5(a). Compared with the plan of driving the new return air roadway, this scheme saves time, shortening the construction period and saving time in the replacement of the working face. The main problem is that the roadway roof 


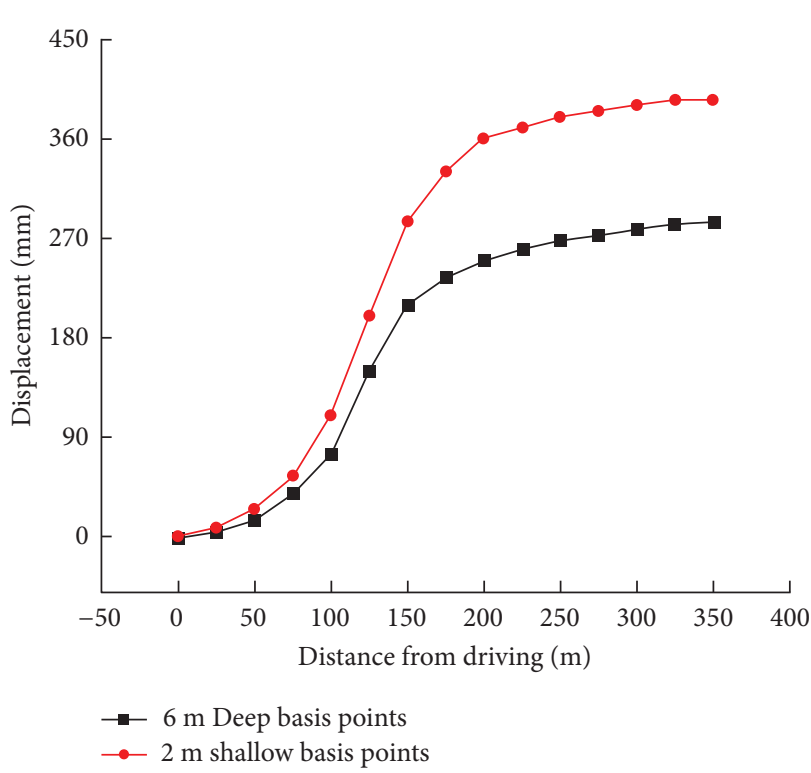

(a)

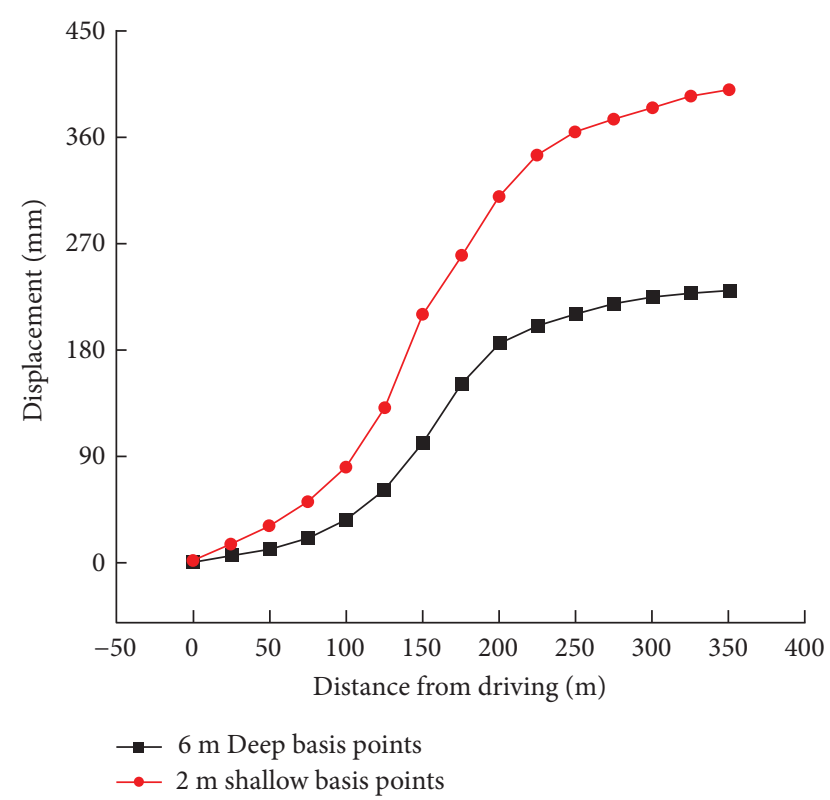

(b)

FIgURE 4: Roof deformation monitoring data from the repaired roadway. (a) Roof monitoring data at $540 \mathrm{~m}$. (b) Roof monitoring data at $640 \mathrm{~m}$.

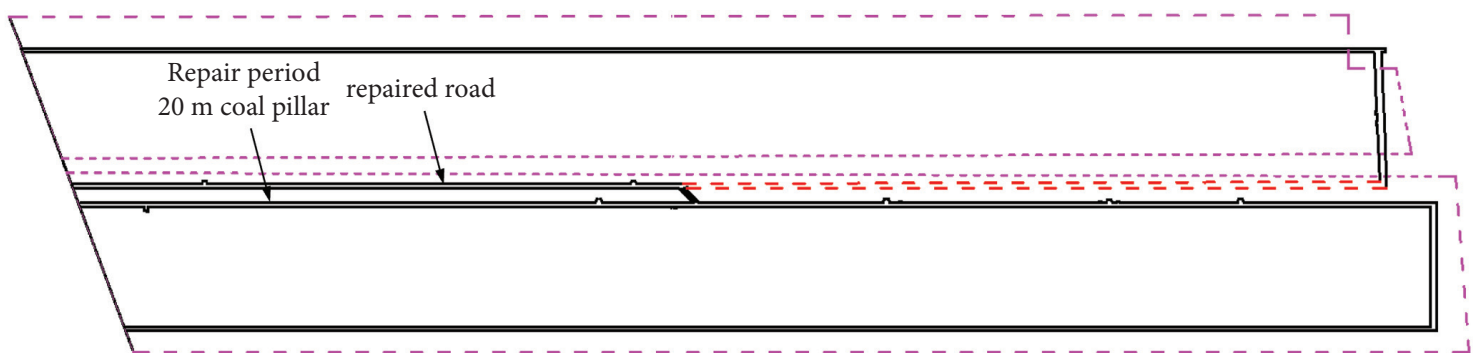

(a)

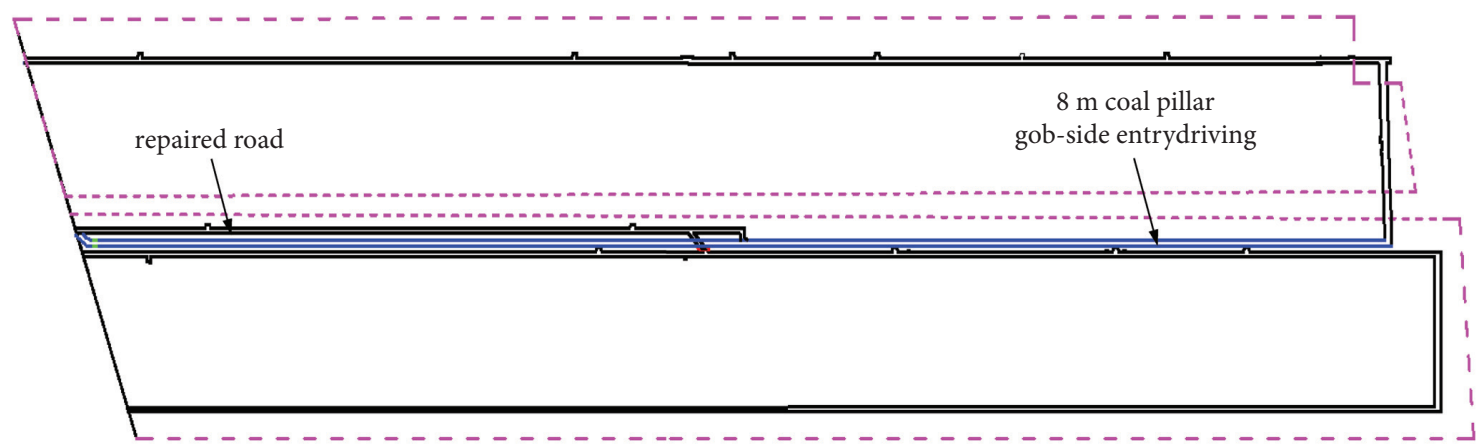

(b)

FIGURE 5: 30503 working face layout scheme. (a) Scheme 1 roadway layout diagram. (b) Scheme 2 roadway layout diagram.

control problem during subsequent roadway driving and the roadway dynamic pressure control problem during the mining period become increasingly complicated due to the influences of the overlying $2 \#$ coal seam, the $20 \mathrm{~m}$ wide legacy coal pillar, and the $20 \mathrm{~m}$ wide coal pillar in the current coal seam.
3.1.2. Drive the New Return Air Roadway. This plan is to drive a new roadway, leaving an $8-\mathrm{m}$ coal pillar between the 30501 working face; the roadway layout is shown in Figure 5(b). Compared with Option 1, this solution can avoid the high-stress area caused by the upper $2 \#$ coal pillars and at the same time recover 650,000 tons of material 


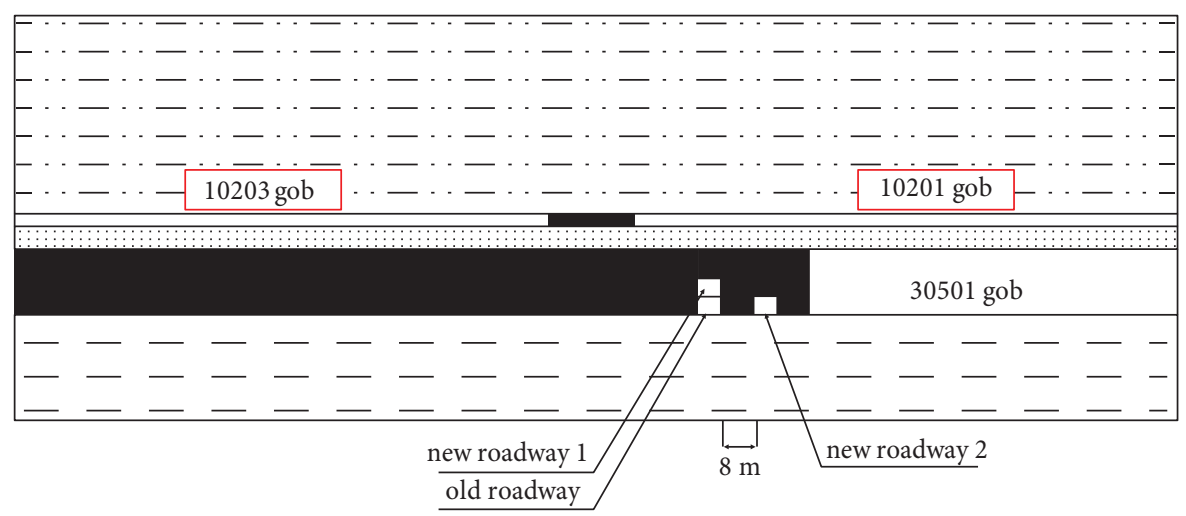

FIGURE 6: Calculation model of the return air roadway in the Tashan China coal mine.

otherwise left in coal pillars. The main problem with this scheme is that the working face will cross the 30501 original return air roadway during the driving period, which may cause danger.

\subsection{Numerical Analysis of Roadway Stability under Different Arrangements}

3.2.1. Establishment of Numerical Model. To determine the influences of different roadway layouts in the 30503 working face on the working face driving, 3DEC simulation software was used to establish a three-dimensional numerical model. The model measures $272 \mathrm{~m} \times 9 \mathrm{~m} \times 60 \mathrm{~m}$ (length $\times$ height $\times$ width). To improve the efficiency of calculation, considering symmetry, half the length of the working face and $150 \mathrm{~m}$ length of the simulated working face were taken along each side of the coal pillar (Figure 6). The boundary and bottom of the model were fixed, and the top was subject to a stress boundary condition. The self-weight stress of $10 \mathrm{MPa}$ was simulated on the top of the model. The commonly used composite Mohr-Coulomb model considering tensile failure, which can better describe the mechanical properties of coal and rock, was selected [35]. The parameters in the numerical simulation were modified based on laboratory measurements (Table 1). The old roadway represents the 30501 roadway and the original return air roadway, which has been filled with fine coal. The new roadway 1 denotes the return air roadway restored in Option 1 , and the new roadway 2 is the new return air roadway to be excavated in Option 2. The horizontal distance between the new roadway 1 and the new roadway 2 is $8 \mathrm{~m}$, and the horizontal distance between the new roadway 2 and the end of the 30503 working face is $8 \mathrm{~m}$.

3.2.2. Simulation Process. According to the historical mining sequence of the working face, the simulation analysis is conducted as follows:

(1) After the model is established, the initial stress field is calculated to balance, excavate the gob on the left and right sides of the $2 \#$ coal pillar, excavate 30501 working face, and calculate the new equilibrium associated therewith;
(2) Excavate the old roadway, observe the deformation and collapse characteristics of the old roadway, and then backfill the old roadway and calculate the new equilibrium associated therewith;

(3) Excavate the new roadway 1, simulate the advance of the 30503 working face, and measure the stability of the new roadway 1 during mining recovery;

(4) If the new roadway 1 cannot meet the recovery safety requirements of the 30503 working face, the new roadway 2 shall be excavated after roadway 1 has been stabilized. Then, the new roadway 1 (without filling), the stability of the new roadway 2 during excavation, and the recovery at the 30503 working face are analyzed.

(5) If the new roadway 1 (without filling) cannot meet the recovery safety requirements of the 30503 working face, the fill command is used to fill new roadway 1 after the excavation of new roadway 2 has been stabilized. After calculating the new equilibrium associated therewith, the advance of the 30503 working face is simulated, and the stability of new roadway 1 and new 2 during the recovery period of 30503 working face after filling is assessed.

Due to historical reasons, the vertical distance between the old roadway and the new roadway 1 is $-2 \sim 6 \mathrm{~m}$, so this simulation can divide the distance between the old roadway and the new roadway 1 into five situations: $-2,0,2,4$, and $6 \mathrm{~m}$. Considering the loss of top coal at the end, the final $4 \mathrm{~m}$ is treated as being mined without caving.

\subsubsection{Simulation Results Analysis}

(1) Stability Analysis of Old Roadways. After the gob on the left and right sides of the 2\# coal is formed, the 30501 working face is excavated, and the deformation and collapse of the overall stope are shown in Figure 7. After completion of coal seam mining, the overlying rock above the working face collapsed to form a gob, which destroyed the equilibrium in the original rock. According to the classic theory of mine pressure, the stress in the length direction of the working face is transferred to the solid coal on both sides of 
TABLE 1: Physicomechanical parameters of the coal rock block.

\begin{tabular}{|c|c|c|c|c|c|c|}
\hline Coal rock seam & $\begin{array}{c}\text { Density } \\
\left(\mathrm{kg} \cdot \mathrm{m}^{-3}\right)\end{array}$ & $\begin{array}{c}\text { Young's modulus } \\
(\mathrm{GPa})\end{array}$ & $\begin{array}{l}\text { Poisson's } \\
\text { ratio }\end{array}$ & $\begin{array}{c}\text { Cohesion } \\
(\mathrm{MPa})\end{array}$ & $\begin{array}{c}\text { Internal friction } \\
\text { angle }\left({ }^{\circ}\right)\end{array}$ & $\begin{array}{c}\text { Tensile strength } \\
(\mathrm{MPa})\end{array}$ \\
\hline Sandy mudstone & 2420 & 25.01 & 0.25 & 2.60 & 55.26 & 6.32 \\
\hline Siltstone & 2738 & 39.23 & 0.15 & 3.27 & 61.42 & 8.65 \\
\hline Clastic rock & 2147 & 26.07 & 0.23 & 2.55 & 52.45 & 7.41 \\
\hline Silty sand, sandy mudstone & 2180 & 27.42 & 0.20 & 2.95 & 55.45 & 68.3 \\
\hline 2 coal & 1290 & 14.43 & 0.40 & 1.20 & 37.18 & 2.15 \\
\hline Aged mudstone & 2287 & 17.97 & 0.24 & 2.55 & 42.45 & 4.06 \\
\hline $3-5$ coal & 1310 & 15.32 & 0.37 & 1.20 & 39.37 & 2.80 \\
\hline Sandy mudstone & 2120 & 24.28 & 0.21 & 2.41 & 40.26 & 6.29 \\
\hline $\begin{array}{l}\text { High water content filling } \\
\text { material }\end{array}$ & 1310 & 10.41 & 0.31 & 0.884 & 30.5 & 1.05 \\
\hline
\end{tabular}

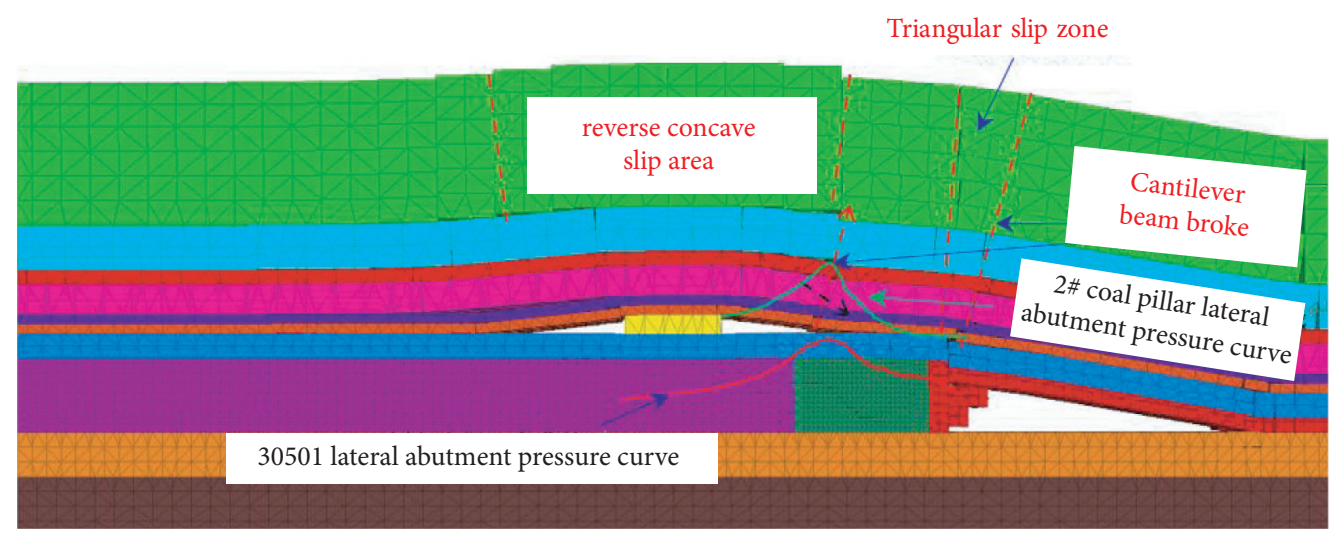

FIGURE 7: Migration of overlying rock during formation of 2\# coal and 30501 gob.

the gob, causing deformation of the surrounding rock of the stope, during which the working face of the lower section is affected by the supporting pressure [36-39].

The distribution and magnitude of lateral abutment pressure are mainly controlled by the cantilever beam structure in the overlying rock. The peak value of the abutment pressure before the gob is stable is larger than that after stabilization, but the extent of the area subject to stress reduction before achieving stability is smaller [40-43]. Figure 7 shows that due to the influence of the $2 \#$ coal pillar, there is a reverse convex slip zone formed by the break of the cantilever beam above the $2 \#$ coal pillar. The movement in this area is characterized by the overall local shearing and sliding movement on both sides of the coal pillar and turning and sinking to the gob on both sides; there is a horizontal force transmitted between the rock mass above the coal pillar. The cantilever beam breaking line is $15-20 \mathrm{~m}$ from the edge of the $2 \#$ coal pillar. The inverted convex slip zone slips to the gob with the stability of the gob, and the rock rotates and slips to the gob at the boundary of the fracture-development zone and the fracture zone, that is, the moving boundary is the hinge point rotating and sliding to the gob. When the broken block in the inverted convex slip zone is in contact with the broken block in the gob, the gob will provide a supporting force (and friction) on the broken area. When the broken block in the inverted convex area cannot make contact with the broken block in the gob, the broken block in the inverted convex area will continue to rotate and slide toward the gob, with the moving boundary line as the hinge point, forming an irresistible rotational deformation and pressure.

After the 30501 working face has been stabilized, the end structure of the working face is subjected to the sinking of the middle of the gob and its self-weight to form a triangular slip zone. The movement of the triangular slip zone is characterized by overall lateral rotation and subsidence in the gob, which is related to the horizontal force exerted by the rock mass above the coal pillar. After the gob is stabilized, the peak value of the lateral abutment pressure has decreased and its zone of influence has increased. The reason for the increase in the range is that the extent of the plastic zone is increased due to the influence of the high value of the abutment pressure. As a result, the range of influence of lateral support pressure increases after the gob is stabilized.

If the roadway is driven in the old roadway position, as shown in Figure 8, due to the combined action of the inverted convex breaking block and the lateral supporting pressure of the 30501 working face, the broken block will continue to slide to the side of the 30501 gob, and a fracture will be generated above the roadway, which breaks the roof of the roadway, making it very difficult to maintain. Unless as time goes by, the roadway can be maintained after the broken block in the inverted convex area and the gob has come into contact, there is also the risk that the moving boundary of the inverted convex slip zone will start again after the second disturbance to the 30503 working face. In 


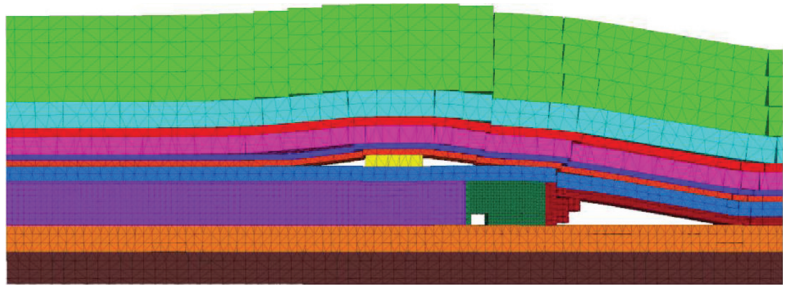

Figure 8: Overlying rock migration during the formation of the old roadway.

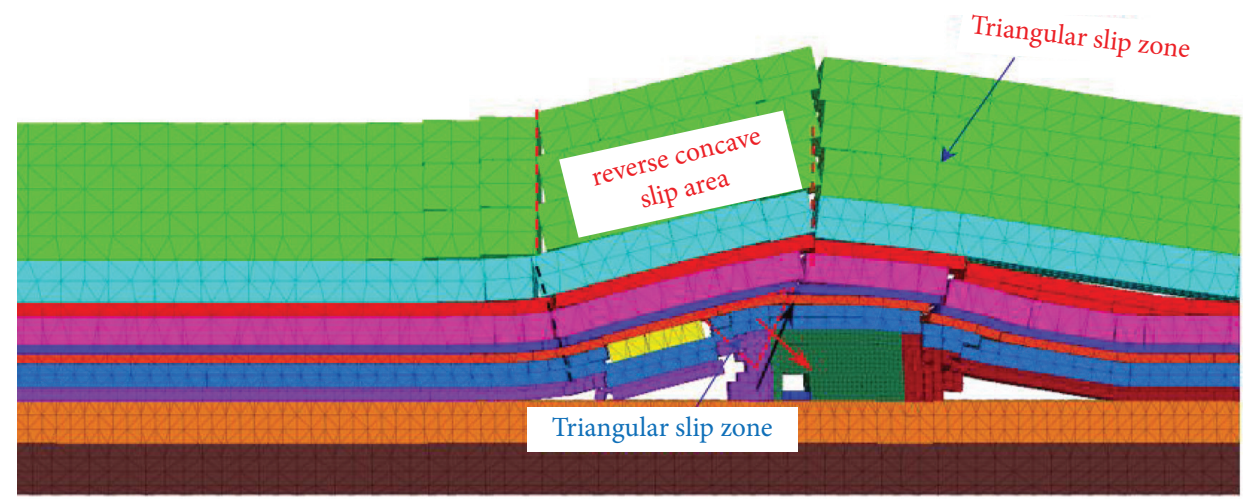

(a)

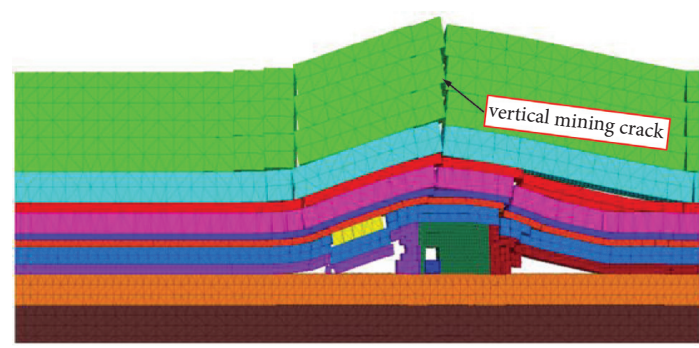

(b)

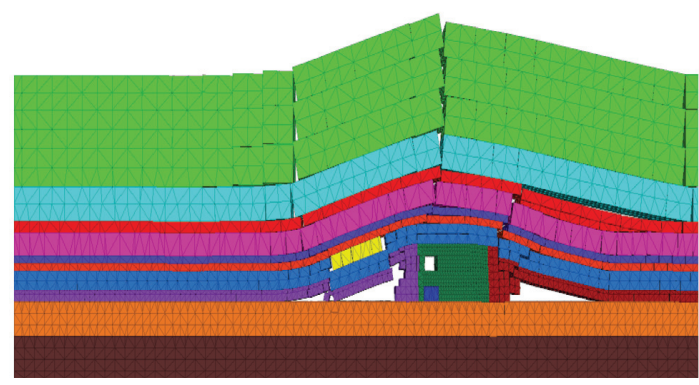

(d)

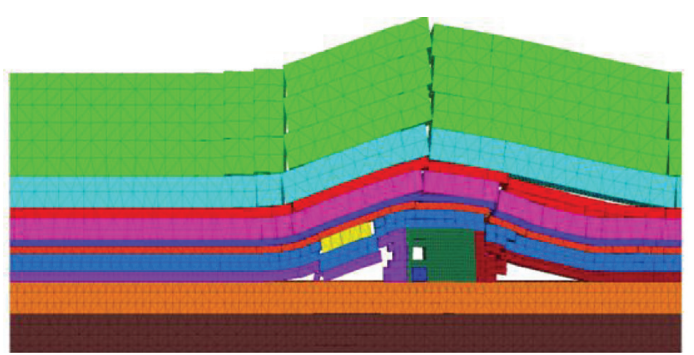

(c)

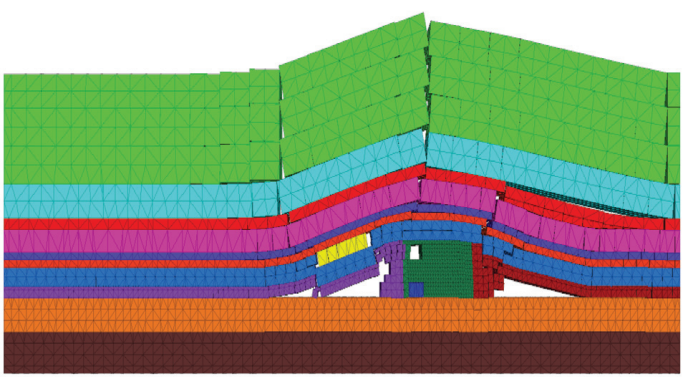

(e)

Figure 9: Overlying migration caused by mining in the 30503 working face. (a) $H=-2 \mathrm{~m}$. (b) $H=0 \mathrm{~m}$. (c) $H=2 \mathrm{~m}$. (d) $H=4 \mathrm{~m}$. (e) $H=6 \mathrm{~m}$.

the process of driving the old return air roadway on-site, the roadway roof is severely damaged and caved, which prevents recovery of the working face.

(2) Stability Analysis of New Roadway 1. The old roadway is backfilled, the new equilibrium associated is calculated, and then the new roadway 1 is excavated. Numerical results show that the excavation of new roadway 1 must withstand the sliding influence of the inverted convex slip zone with the moving boundary line as the cementation point, but it is not enough to cause large deformation and migration in the inverted convex slip zone; increasing the strength of any supports barely ensures the safety of the excavation.

The conditions of different distances between the old roadway and the new roadway 1 are simulated, the 30503 working face is mined, and the excavation is stopped at a position $9 \mathrm{~m}$ from the new roadway along the length of the working face. The migration of the overlying rock formed after the recovery of the 30503 working face under the driving conditions of new roadway 1 is shown in Figure 9. It can be seen that, due to the recovery of the 30503 working face, the inverted convex slip zone above the $2 \#$ coal pillar is 
activated for the second time and continuously rotates and slips to the side of the 30503 gob, gradually forming two slip modes with the 2\# coal gob as the hinge point. One is the vertical fissure above the gob, and the other is a new triangular slip area bordered by coal and rock above the $2 \#$ coal pillar, 2\# coal gob, and the incline above the new roadway 1. The two modes of slipping are related to the horizontal force on the interlayer coal and rock mass above the new roadway 1. The vertical load acts to push the mass toward the 30503 gob, shedding more load onto the new roadway and causing the new triangular slip zone surrounding rock to rotate and slip instantly. The instability of the hinge point induces the vertical fissure and the cut-and-fall dislocation of the new roadway, and there is a severe risk of roof leakage and compression of the support. By then, maintaining this new roadway will be very difficult.

At the same time, triangular slip area formed by mining in 30501 working face undergoes rigid body rotation and subsidence to the goaf side of the 30501 working face. When the broken block in the triangle slip area makes contact with the broken block in the goaf, the gob will provide a supporting force (and friction) on the broken area, thus closing the triangular slip zone, and extending the zone of influence while the lateral support pressure is reduced. The block itself and the overlying load above the stable contact do not need to be completely borne by the coal pillar. Besides, regardless of the distance between the old roadway and the new roadway 1 , a vertical mining crack with a length of more than $50 \mathrm{~m}$ will be generated above the new roadway 1 when the 30503 working face is recovered: this mining crack will be connected to the new roadway, forming an irresistible cut-and-fall dislocation.

(3) Stability Analysis of the New Roadway 2 When the New Roadway 1 is Not Filled. Since the excavation of the new roadway 2 does not change the overall structure of the stope, the triangular slip area and vertical cracks formed by the recovery of the 30503 working face persist. When new roadway 2 is excavated without filling new roadway 1 , there is still a vertical mining crack with a length of more than $50 \mathrm{~m}$ in the roof rock layer of new roadway 1 , as illustrated in Figure 10. Although the left-hand side of new roadway 1 is recovered in the form of top coal caving when the 30503 working face is recovered, the triangular slip zone formed by the mining still exists. The hidden danger of cut-and-fall dislocation caused by the sudden instability of hinge point and the connection between vertical fracture and new roadway 1 remains. The sliding instability of the structure will inevitably result in a drastic change in the external mechanical environment and cause the violent movement of the rock above the coal pillar, concentrating the stress thereon.

New roadway 2 is offset by $8 \mathrm{~m}$ to the right, just staggering the vertical fissures located in the top slab of new roadway 1 , placing the roadway in the zone of decreasing stress; the roadway itself is more stable and lends greater support. Due to the release of the overall pressure of the inverted convex slip and the cushioning effect of the new roadway 1 , the triangular slip zone at the end forms a plastic cement structure, which affords a certain protective benefit to roadway 2 .

(4) Stability Analysis of New Roadway 2 When Filling New Roadway 1. Considering that, when passing through the empty roadway (roadway repair section) during the recovery period, it is affected by the leading pressure and the overlying 2\# coal pillar, which causes front roof leakage of the working face frame. Second, the ultra-high section of the empty roadway is likely to form a windless zone. In addition, local sections fall in advance due to the influence of mining-induced advance stress, forming blind roadways, all causing harmful gas accumulation [44-47]. For this reason, the empty roadway in the working face, that is, the repair section of the 30503 return air roadway, must be filled before mining.

Figure 11 shows the movement of the overlying rock in the distributed excavation of the 30503 working face after the filling of the new roadway 1 . Based on the above analysis, the excavation and filling of the roadway have little effect on the movement of the overlying rock, and the recovery of the working face is the main factor influencing the movement of the overlying rock. After filling the new roadway 1, the triangular slip zone and vertical fracture formed by mining in 30503 working face remain. For the new roadway 1, the filling material cannot fill the void and in a plastic state it produces a cushioning effect. Therefore, when the shearer cuts the remaining coal seam, it will inevitably cause the surrounding rock in the new triangular slip zone to rotate, slip, and gradually penetrate any vertical mining fissures. However, the triangular slip zone breaking block, the filling body of the new roadway 1 , and the $2 \#$ coal gob are in full contact. The filling body provides a supporting force (and friction) on the broken zone, causing the slip zone to close, and extending the plastic zone. This eliminates the hidden danger of cut-and-fall dislocation caused by the sudden instability of the hinge point, which causes the vertical crack to pass through the new roadway 1 , avoiding the risk of roof leakage and compression of the support. Combining the above analysis, it can be concluded that after filling the new roadway 1 , due to the release of the overall pressure on the inverted convex slip by the new roadway 1 , and the cushioning of the top coal and the filling body, the triangular slip zone at the end forms a plastic cemented structure, which protects the new roadway 2 to a certain extent.

When the working face is recovered, displacement measuring points are arranged within $10 \mathrm{~m}$ ahead of the new roadway 1 and the new roadway 2 , extracting the displacement of the roof and bottom of the roadway and the two sides when the 30503 working face is mined to $10 \mathrm{~m}$ ahead (Figure 12). When mining at the working face, the overall deformation of the new roadway 1 in scheme 1 is much greater than that when driving along the gob. When scheme 1 is adopted, the sinking of the roadway roof is the main form of deformation, which corresponds to the site conditions, indicating that roof fall and other accidents are likely to occur. In the second scheme, when the filling of new roadway 1 is chosen, the overall deformation of the roadway is the smallest, and the roof deformation of the roadway is 


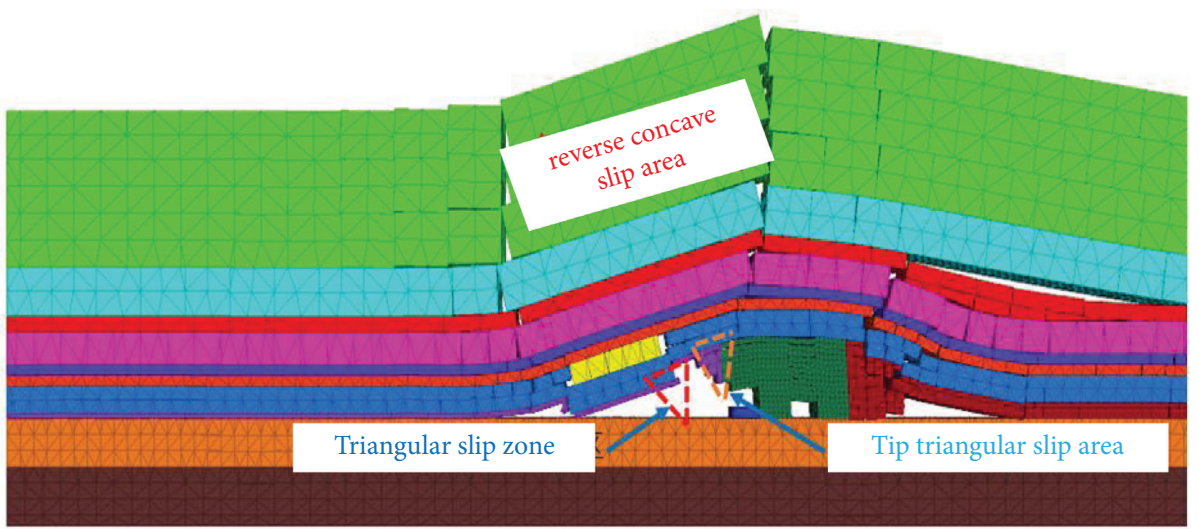

(a)

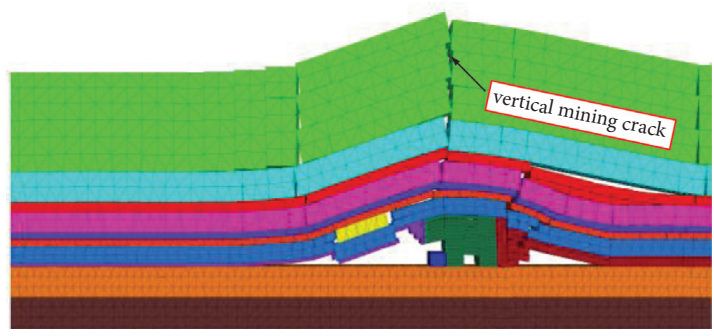

(b)

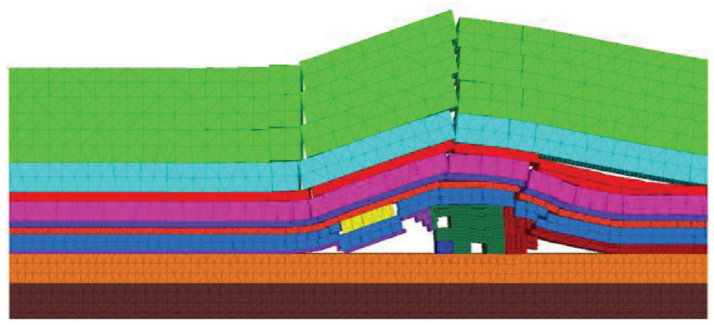

(d)

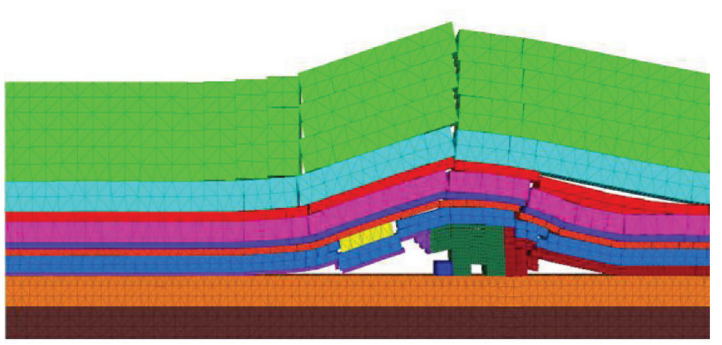

(c)

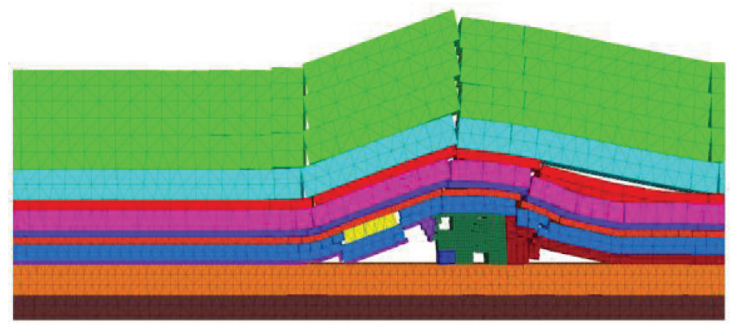

(e)

FIGURE 10: Overlying rock movement caused by recovery at the 30503 working face and its impact on new roadway 2 (new roadway 1 remains unfilled). (a) $H=-2 \mathrm{~m}$. (b) $H=0 \mathrm{~m}$. (c) $H=2 \mathrm{~m}$. (d) $H=4 \mathrm{~m}$. (e) $H=6 \mathrm{~m}$.

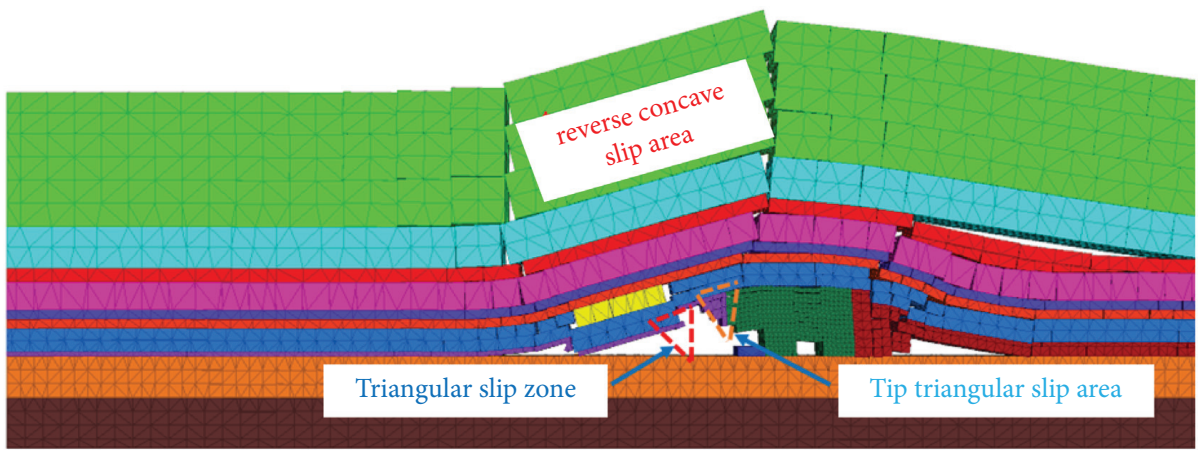

(a)

FIgUre 11: Continued. 


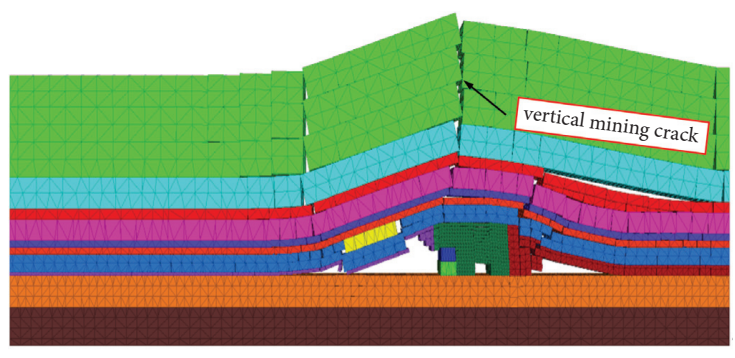

(b)

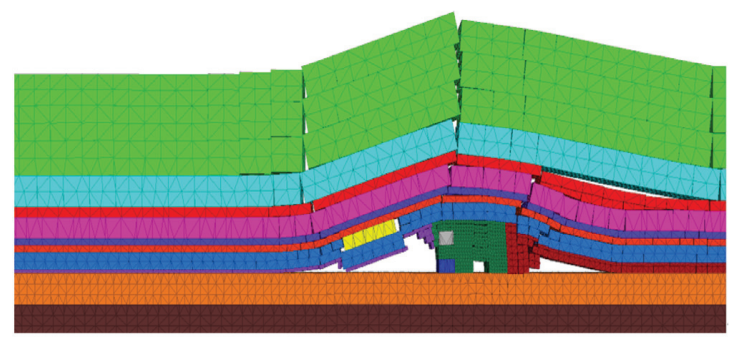

(d)

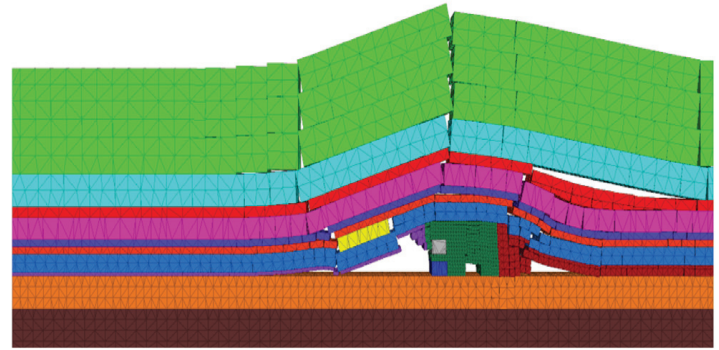

(c)

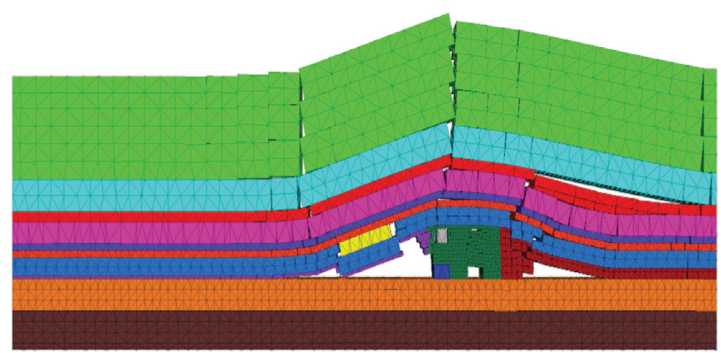

(e)

FIGURE 11: Overlying rock movement caused by recovery at the 30503 working face and its influence on new roadway 2 (after new roadway 1 has been filled). (a) $H=-2 \mathrm{~m}$. (b) $H=0 \mathrm{~m}$. (c) $H=2 \mathrm{~m}$. (d) $H=4 \mathrm{~m}$. (e) $H=6 \mathrm{~m}$.

stable. The maximum deformation is $95 \mathrm{~mm}$, which is reduced by nearly half compared with the case without filling.

Combining the above simulation results, it is apparent that under the influence of the $2 \#$ coal pillar, there is a vertical mining crack with a length of more than $50 \mathrm{~m}$ directly above the roadway repair section of the 30503 working face, which is the key to the deformation and damage of the roadway repair section. Mining of the 30503 working face will cause the mining fissure to be connected with the repaired section of the roadway, forming an artificially irresistible cut-and-fall dislocation. Changing the location of the roadway repair section to avoid the influence of vertical mining cracks is the best choice when trying to control the stability of the return air roadway in the 30503 working face. Simultaneously, the simulation results show that when selecting the new roadway 2 as the return air roadway and filling the new roadway 1 , the maintenance workload of the return air roadway is minimal.

\subsection{In Situ Verification of the Roadway Optimization Scheme}

\subsubsection{Deformation Analysis during Roadway Excavation.} The roadway was rearranged at chainage $+955 \mathrm{~m}$ along the working face. The starting point of the roadway driving along the gob after the turn was at chainage $+1020 \mathrm{~m}$; we first excavated from chainage $+1020 \mathrm{~m}$ to the side of the cut-off side of the working face and then reversed the excavation from the side of the roadway, to complete the return air roadway. The crossobservation method was used to monitor the deformation of the repaired roadway and the roadway driving along the gob before and after the roadway turns. The layout of the monitoring points is illustrated in Figure 13.
The deformation of monitoring points within $770 \mathrm{~m}$ to $1065 \mathrm{~m}$ along the return air roadway is illustrated in Figure 14. Figure 14(a) indicates that the deformation of the coal roadway roof and floor is between 13 and $65 \mathrm{~mm}$ during excavation of the roadway. When driving along the gob, the deformation of the roof and floor is between 0 and $13 \mathrm{~mm}$, and the deformation of the roof and floor in the turning section is between 0 and $15 \mathrm{~mm}$. The deformation of the two sides of the repaired roadway is between 5 and $25 \mathrm{~mm}$ (Figure 14(b)), and the deformation of the roadway along the gob and the turning section is between 3 and $13 \mathrm{~mm}$. Combining these data with the above analysis, the deformation of the roadway along the gob is found to be significantly less than that of the repaired roadway during roadway excavation.

\subsubsection{Analysis of Support Data in Overfilling Roadway during} Mining. The filling and reinforcement of the 30503 return air roadway repair section relied on the use of an ultrahigh water content filling material, which was mixed with water to form a pumped slurry. The water-cement ratio of the slurry was $6: 1$, and the uniaxial compressive strength of the condensate was greater than or equal to $1.0 \mathrm{MPa}$. We arranged the pumping station in the 30503 return air roadway and filled the roadway from the north side of the roadway to the south side in turn to establish a closed grouting wall every $20 \mathrm{~m}$ in the roadway (a $600-\mathrm{mm}$-thick brick wall was required for airtightness with cement used to seal the gap between the brick wall and the surrounding coal wall). The grouting port was arranged at the top of the closed grouting wall to ensure that the void was tightly filled. 


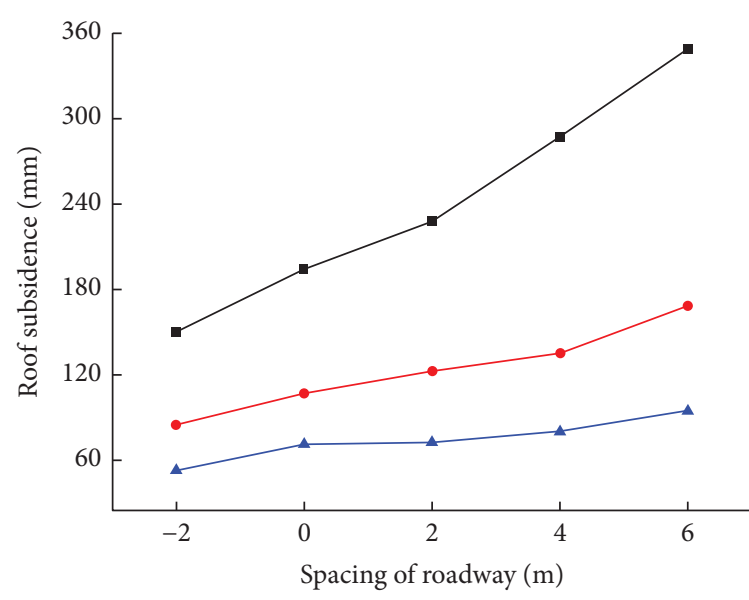

$\rightarrow-$ Only new lane 1 was be excavated in scheme

$\rightarrow$ Scheme 2 does not fill new lane 1

^ـ Scheme 2 fills new 1

(a)

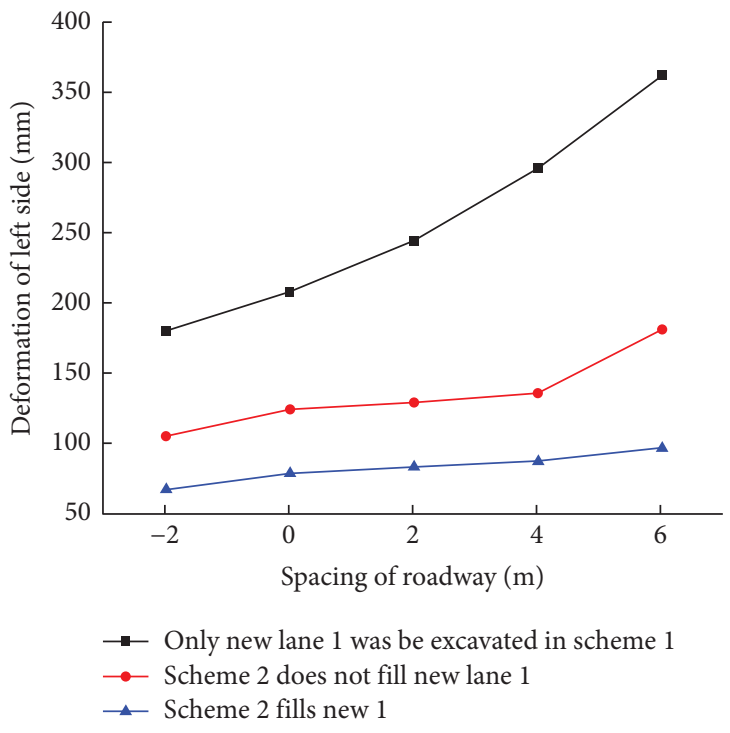

(c)

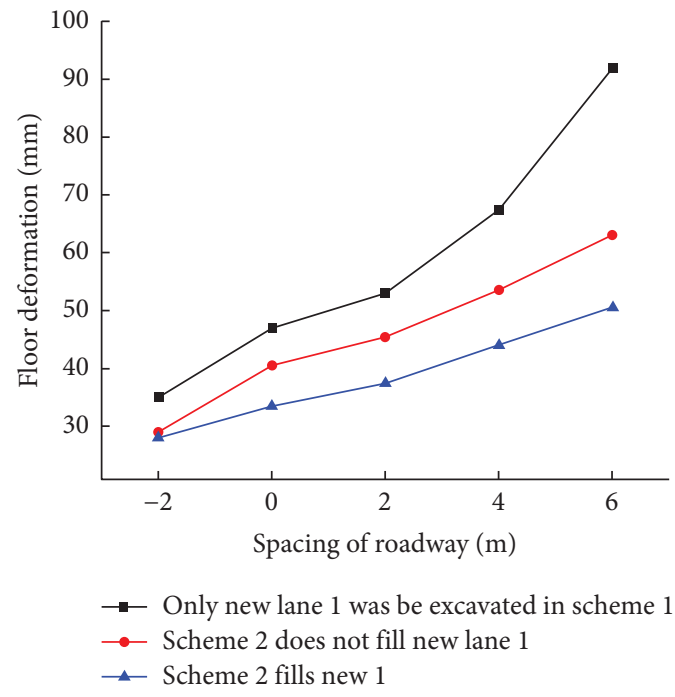

(b)

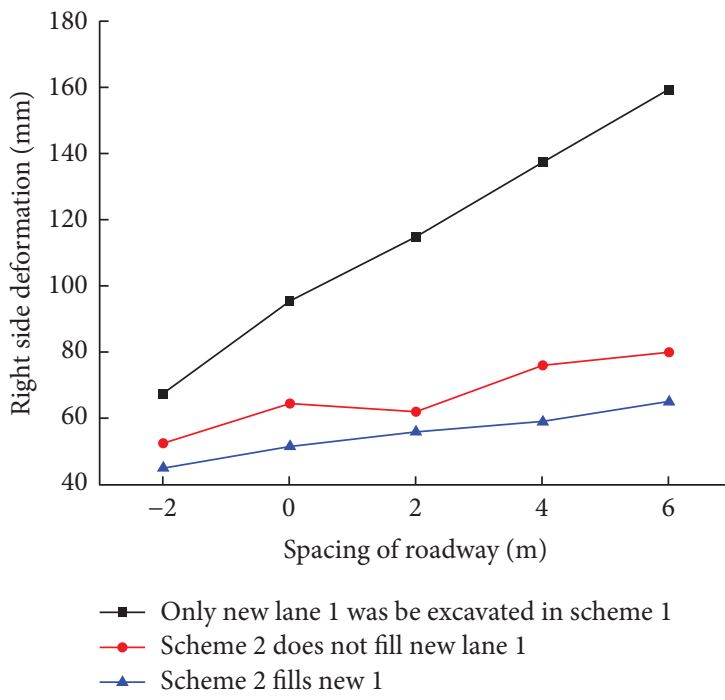

(d)

Figure 12: Deformation of the roadway under different layouts of the return air roadway. (a) Roof deflection. (b) Floor deflection. (c) Deformation of the left side. (d) Deformation of the right side.

The 30503 working face recovered the voided roadway area on 19 January: the support data within one month before and after the working face passed the filling roadway were classified, and different levels of support data were color-coded (Figure 15). After the working face passed through the filling roadway, the support pressure thereon increased to a certain extent, indicating that the filling roadway had affected working face mining, but the increase in the pressure on the support only reached a maximum value of $28 \mathrm{MPa}$, which was only $16 \%$ higher than the setting pressure of $24 \mathrm{MPa}$. In February, the support pressure on the filling roadway area came to match that before recovery, suggesting that the high water content material had achieved a better cushioning effect in the backfill area and could deform in coordination with the roadway roof under the action of the applied mining stress.

3.3.3. Analysis of Deformation of Overfilled Roadway during the Recovery Period. The cross-observation method was used to monitor deformation of the return air roadway when passing the filling roadway (Figure 16). Before and after the 


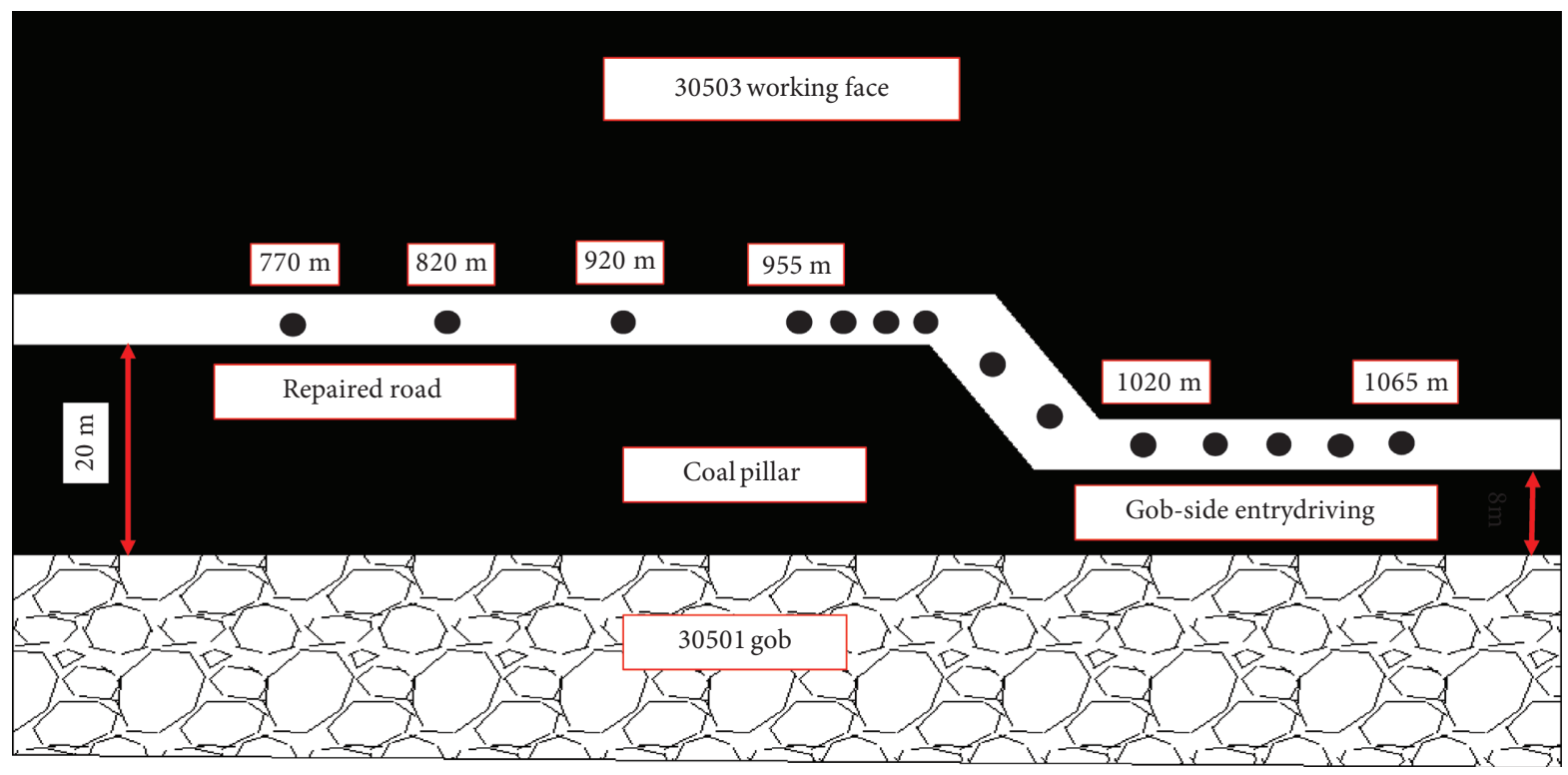

FIGURE 13: Schematic diagram of roadway deformation monitoring points.

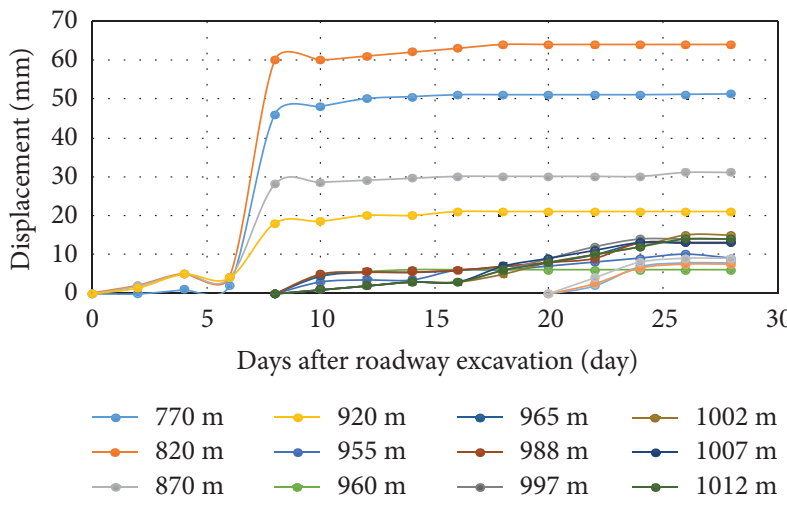

(a)

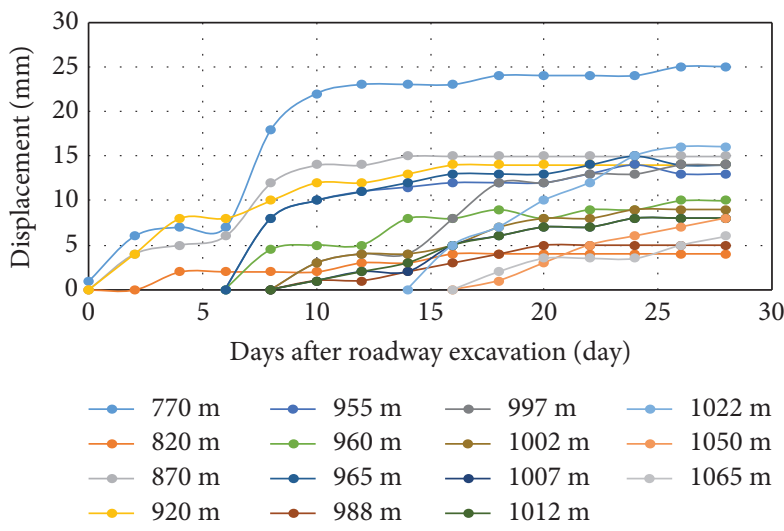

(b)

Figure 14: Deformation of roadways when using different layouts. (a) Roof and floor approach. (b) Two-sided approach.

working face crosses the filling roadway, the deformations of the roof and floor of the roadway and the two sides are similar, indicating that the roadway is broken during the recovery process, and the existence of the filling roadway does not affect the return air roadway. During the recovery of the working face, the maximum approach of the two sides is $650 \mathrm{~mm}$, which appears about $100 \mathrm{~m}$ in front of the working face, and the maximum approach of the top and floor plates is $320 \mathrm{~mm}$, both appearing about $100 \mathrm{~m}$ in front of the working face. The deformation of the roadway tends to be stable some $300 \mathrm{~m}$ ahead of the working face. This shows that, when the working face passes through the filling roadway, it has no major influence on the deformation of the 30503 return air roadway. 


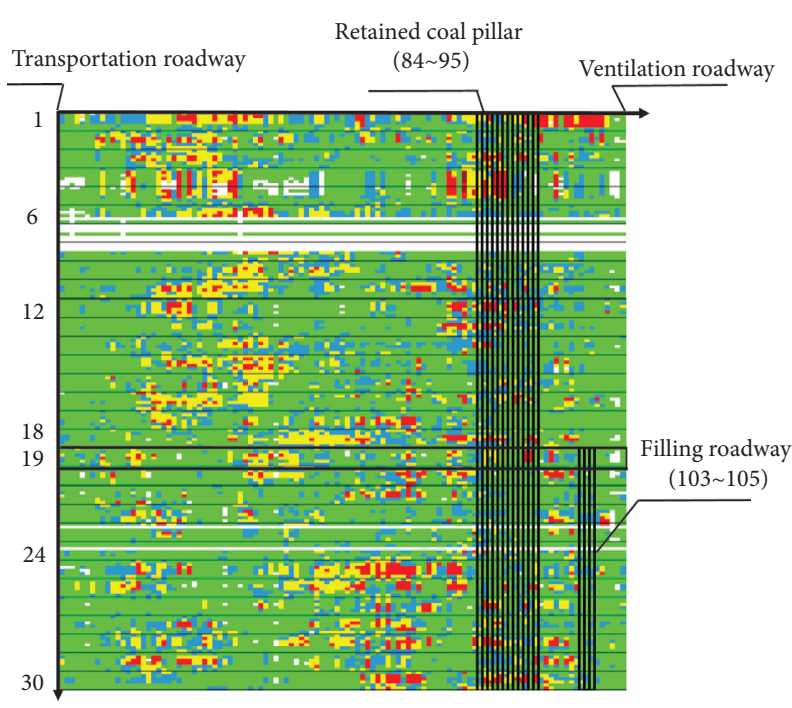

(a)

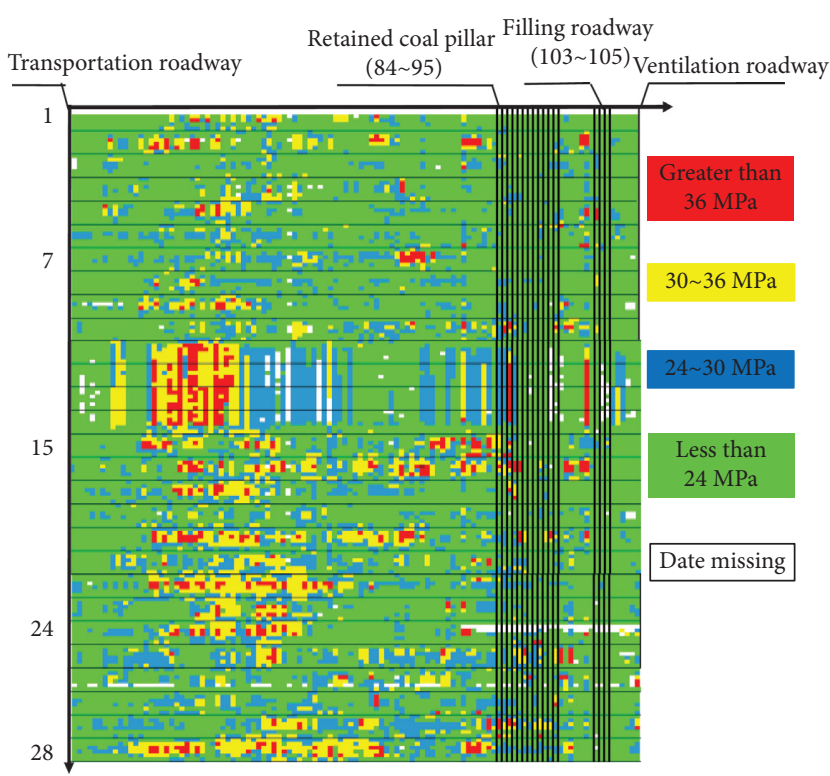

(b)

Figure 15: Data from the hydraulic support before and after overfilling the roadway. (a) Data from the hydraulic support in January. (b) Data from the hydraulic support in February.

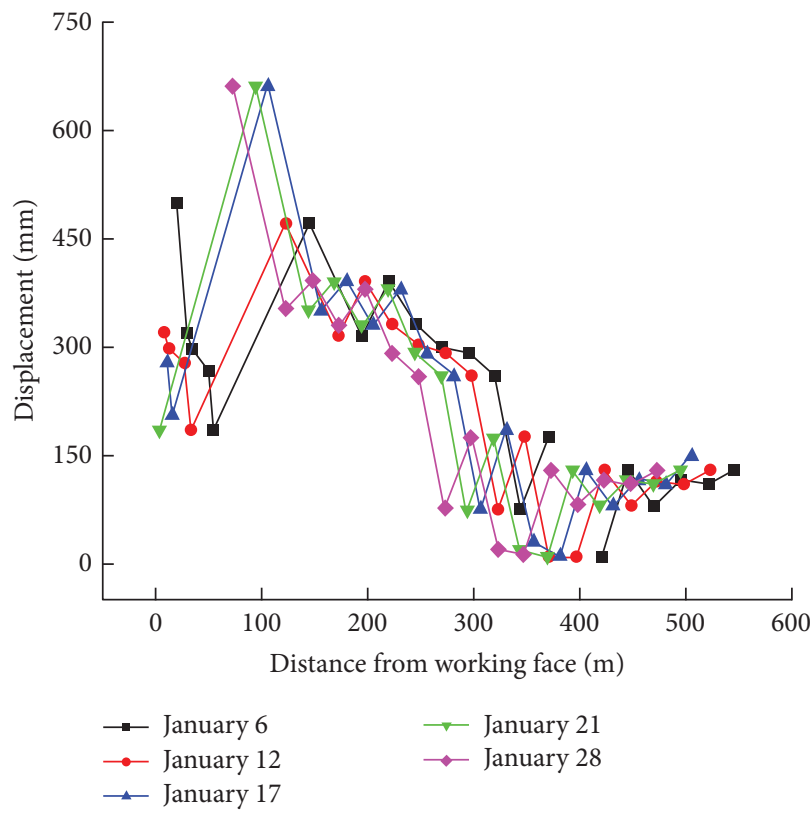

(a)

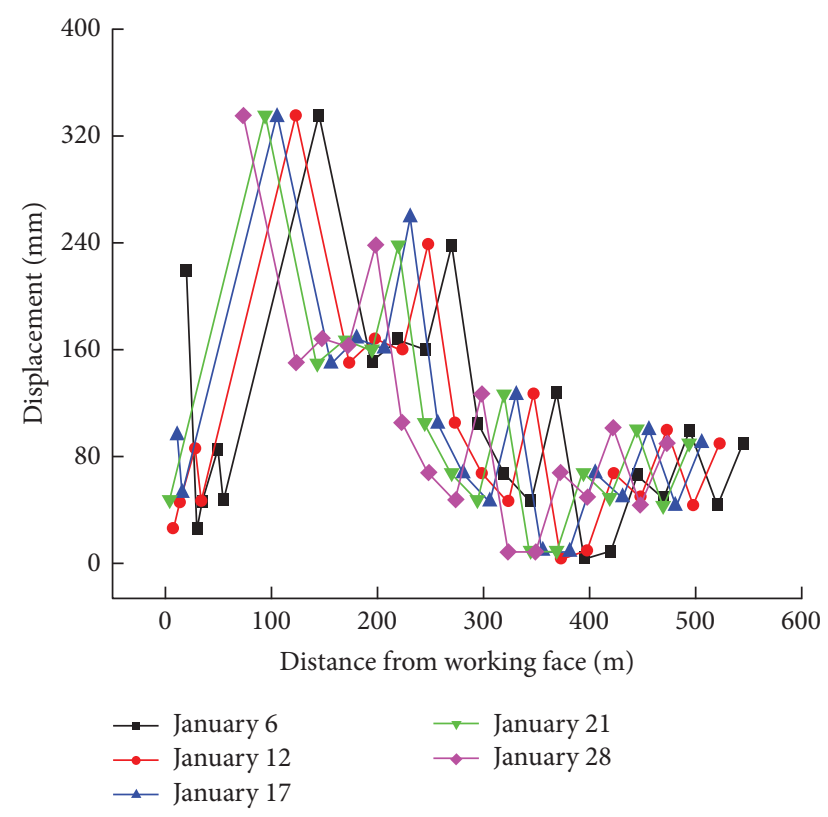

(b)

Figure 16: Deformation data from the return air roadway. (a) Roof and floor approach. (b) Two-sided approach.

\section{Conclusion}

The layout of the return air roadway in the 30503 working face of the coal pillar under the 3-5\# coal seam remaining from the $2 \#$ coal seam of Tashan Coal Mine was optimized. The main conclusions can be drawn as follows:

(1) The results of drilling and deformation data show that the subsidence of the roof is characterized by rapid deformation, increasing layer separation, and a wide range of influence. The compound action of the overlying goaf and adjacent working face mining is the main reason for the damage to the restored roadway.

(2) In view of the multiple roof leaks that occurred during the repair of the excavated roadway in Tashan Coal Mine, the scheme of goaf excavation and an old 
roadway excavation is proposed. The results show that when the restoration roadway excavation technique is adopted, due to the mining of the working face, a vertical mining crack of more than $50 \mathrm{~m}$ is formed above the repaired roadway. When the goaf excavation scheme is adopted, the roadway will stagger with mining-induced fractures and put it in the area of reduced stress. By comparing the deformation and failure characteristics of roadways with different layouts, the roadway deformation is minimized (and is more stable) when the roadway is excavated along the goaf and filled with an old roadway.

(3) Besides that, to ensure the safety of miners when the working face passes through the repaired roadway, the repaired roadway should be filled with high water content materials. During the pressure period, the pressure of the stent is not much different from that of the adjacent area, indicating that the high water content material has played a better role as a cushion. Deformation data captured during roadway excavation, and when the working face passes through the filling roadway, prove that the effects of the application of a roadway along the gob and filling a repaired roadway are better.

\section{Data Availability}

The data used in this paper come from field measurement.

\section{Conflicts of Interest}

The authors confirm that there are no conflicts of interest associated with this publication.

\section{Acknowledgments}

This work was financially supported by the National Natural Science Foundation of China (Grant no. 51634001).

\section{References}

[1] Y. Yu, J. Gao, and W. Shen, "Deformation mechanism and control of lower seam roadway of contiguous seams," Journal Mining \& Safety Engineer, vol. 33, no. 1, pp. 49-55, 2016.

[2] S. Chen and W. Zhu, "Study on double-roadway layout under section coal pillar of ultra-close upper coal seams in Huojitu mine," Journal of Mining and Safety Engineering, vol. 33, no. 3, pp. 467-474, 2016.

[3] Y. Peng and Q. Li, "Floor failure and roadway deformation induced by contiguous coal seams mining at Huopu Mine," Arabian Journal of Geosciences, vol. 13, no. 601, 2020.

[4] H. Yan, J. Zhang, N. Zhou, S. Zhang, and X. Dong, "Shaft failure characteristics and the control effects of backfill body compression ratio at ultra-contiguous coal seams mining," Environmental Earth Sciences, vol. 77, no. 458, 2018.

[5] M. Sun, X. Zhang, W. Zheng, and X. Zhang, "Study on causing disaster and removing danger for stress concentration of overlying residual coal pillar in ultra-close multi-seam," Geotechnical \& Geological Engineering, vol. 37, no. 5, pp. 4009-4017, 2019.
[6] N. C. Zhang, Stress Redistribution Law of Floor Rock under Chain Pillar and its Application in Multi-Seam Mining, China University of Mining and Technology, Xuzhou, China, 2016.

[7] Z. Cheng, H. Ma, C. Sang, and Y. Liu, "Experimental research on dynamic evolution characteristics of roof movement and mining-induced stress of superimposed mining in a close distance coal seam group," Geotechnical \& Geological Engineering, vol. 39, no. 1, pp. 13-24, 2021.

[8] R. Liu, B. Li, and Y. Jiang, "A fractal model based on a new governing equation of fluid flow in fractures for characterizing hydraulic properties of rock fracture networks," Computers and Geotechnics, vol. 75, pp. 57-68, 2016.

[9] M. Ju, D. Wang, J. Shi, L. Jianchun, Y. Qiangling, and L. Xing, "Physical and numerical investigations of bedding adhesion strength on stratified rock roof fracture with longwall coal mining," Geomechanics and Geophysics for Geo-Energy and Geo-Resources, vol. 7, no. 24, 2021.

[10] C. Wang, M. Hu, N. Zhang, and X. Wang, "Optimization of gateroad layout under remnant structures in longwall undermining based on slip line field theory," Arabian Journal of Geosciences, vol. 141704 pages, 2021.

[11] W. Zha, H. Shi, S. Liu, and C. Kang, "Surrounding rock control of gob-side entry driving with narrow coal pillar and roadway side sealing technology in Yangliu Coal Mine," International Journal of Mining Science and Technology, vol. 27, no. 5, pp. 819-823, 2017.

[12] X. Li, Y. Zhao, W. He, L. Li, and F. He, "Study on coal pillar width and surrounding rock control of gob-side entry in extra-thick coal seam," Geotechnical \& Geological Engineering, vol. 38, no. 6, pp. 6855-6868, 2020.

[13] K. Yang and P. Gou, "Research on reasonable width of coal pillars in high strength mining roadway in wantugou mine," Geotechnical \& Geological Engineering, vol. 39, no. 3, pp. 2065-2073, 2021.

[14] Y. Wang, Y. M. Li, Z. L. Yu, H. Zhang, and D. Ding, "Research on the surrounding rock control technology of gob-side entry with a narrow coal pillar reserved in a fully mechanized caving face with large mining height," Geotechnical \& Geological Engineering, pp. 1-16, 2021.

[15] Z. Ma, C. Chen, X. Liang, A. Chen, and W. Song, "Field and numerical investigation on the stability of coal pillars of gobside entry driving with top coal," Arabian Journal of Geosciences, vol. 131193 pages, 2020.

[16] X. Gao, S. Zhang, Y. Zi, and S. N. Khan, "Study on optimum layout of roadway in close coal seam," Arabian Journal of Geosciences, vol. 13, no. 746, 2020.

[17] F.-l. He, Y.-q. Zhao, F.-x. Xie, and J. Liu, "Instability mechanism and control of roadway subjected to severe mining dynamic load with double roadway layout mining face," Geotechnical \& Geological Engineering, vol. 37, no. 4, pp. 2985-2997, 2019.

[18] H. Yan, M.-y. Weng, R.-m. Feng, and W.-K. Li, "Layout and support design of a coal roadway in ultra-close multipleseams," Journal of Central South University, vol. 22, no. 11, pp. 4385-4395, 2015.

[19] Z. F. Song, Y. J. Sun, and X. Liu, "Research on in situ stress measurement and inversion, and its influence on roadway layout in coal mine with thick coal seam and large mining height," Geotechnical \& Geological Engineering, vol. 36, pp. 1907-1917, 2018.

[20] W. Sun, Z. Qin, Q. Li, G. Chen, and T. Li, "Study on optimization of roadway position in pre-mining upper layered concave-convex coal body," Geotechnical \& Geological Engineering, vol. 37, no. 5, pp. 3739-3748, 2019. 
[21] X. J. Liu, X. M. Li, and W. D. Pan, "Analysis on the floor stress distribution and roadway position in the close distance coal seams," Arabian Journal of Geosciences, vol. 9, no. 83, 2016.

[22] Y. Chen, L. Li, Z. Zhou, W. Tu, Y. Zhu, and C. Shang, "Asymmetric deformation characteristics and support scheme design of the surrounding rock in deep roadway," Arabian Journal of Geosciences, vol. 14, no. 556, 2021.

[23] Z. H. Cheng, Q. X. Qi, W. Y. Kong, L. Zhang, W. Ji, and X. Liu, "Study on the reasonable layout of gob-side remained gateway of lower coal seam close to coal seam group," Journal of Mining \& Safety Engineering, vol. 32, no. 3, pp. 453-458, 2015.

[24] D. Z. Kong, Z. H. Wang, and Z. C. Ren, "Determining the optimum position of roadways of full-mechanized caving face in the close distance seams," Journal of Mining \& Safety Engineering, vol. 31, no. 2, pp. 270-276, 2014.

[25] Z. Q. Wang, L. Shi, Y. Su, Z. W. Sun, S. Ziyu, and C. Xu, "Research on surrounding rock control technology of external-misaligned stagger arrangement of roadway in ultrathick seam," Journal of Mining Science and Technology, vol. 3, no. 5, pp. 470-476, 2018.

[26] H. X. Dong, "Surrounding rock control of narrow coal pillar in gob side entry driving with fully mechanized top coal caving mining in extra thick coal seam," Journal of Mining and Strata Control Engineering, no. 3, pp. 1-11, 2021.

[27] T. Guo, H. Feng, Z. Q. Sun et al., "Numerical analysis of the effect of heterogeneity on underground roadway stability under dynamic loads," Shock and Vibration, vol. 2021, Article ID 2738627, 23 pages, 2021.

[28] W. R. He, F. L. He, D. D. Chen, and Q. K. Chen, "Pillar width and surrounding rock control of gob-side roadway with mechanical caved mining in extra-thick coal seams under hard-thick main roof," Journal of Mining \& Safety Engineering, vol. 37, no. 2, pp. 349-358, 2020.

[29] D. Y. Hao, Y. Z. Wu, H. J. Chen, X. W. Chu, and Y. Li, "Instability mechanism and prevention technology of roadway in close distance and extra thick coal seam under goaf," Journal of China Coal Society, vol. 44, no. 9, pp. 2682-2690, 2019.

[30] S. H. Tu, F. T. Wang, F. J. Dou, and Y. Yong, "Fully mechanized top-coal caving: undergr- ound stress at gateways under barrier pillars of an upper coal seam," Journal of China University of Mining \& Technology, vol. 39, no. 1, pp. 1-5, 2010.

[31] B. B. Qin, F. L. He, X. B. Zhang et al., "Stability and control of retracement channels in thin seam working faces with soft roof," Shock and Vibration, vol. 2021, Article ID 8667471, 12 pages, 2021.

[32] G. J. Liu, S. L. Li, Z. L. Mu et al., "Numerical study on the impact instability characteristics induced by mine earthquake and the support scheme of roadway," Shock and Vibration, vol. 2021, Article ID 7697905, 16 pages, 2021.

[33] Y.-M. Zhao, X.-T. Feng, Q. Jiang et al., "Large deformation control of deep roadways in fractured hard rock based on cracking-restraint method," Rock Mechanics and Rock Engineering, vol. 54, no. 5, pp. 2559-2580, 2021.

[34] Q. Jiang, X. Liu, F. Yan, Y. Yang, D. Xu, and G. Feng, "Failure performance of 3DP physical twin-tunnel model and corresponding safety factor evaluation," Rock Mechanics and Rock Engineering, vol. 54, no. 1, pp. 109-128, 2021.

[35] H. B. Zhao, Y. H. Liu, J. Y. Li et al., "Analysis of damage process and zonal failure characteristics of rock mass under floor of isolated coal pillar," Journal of China University of Mining \& Technology, vol. 50, no. 5, pp. 963-974, 2021.
[36] B. Yu, "Structural evolution of breaking roof group of multiple coal seams and its influence on lower coal seam mining," Journal of China Coal Society, vol. 40, no. 2, pp. 261-266, 2015.

[37] Q. Wang, H. Gao, B. Jiang et al., "Research on reasonable coal pillar width of roadway driven along gob in deep mine," Arabian Journal of Geosciences, vol. 10, no. 466, 2017.

[38] N. Fan, J. Wang, B. Zhang, D. Liu, and R. Wang, "Reasonable width of segment pillar of fully-mechanized caving face in inclined extra-thick coal seam," Geotechnical \& Geological Engineering, vol. 38, no. 4, pp. 4189-4200, 2020.

[39] L. Tai, S. Gu, Z. Liu, T. Zou, J. Lu, and C. Chen, "Study on the regularity of ore pressure in overburden hard rock working face of overburden mining on reverse faults," Geotechnical \& Geological Engineering, vol. 39, no. 2, pp. 1591-1601, 2021.

[40] S.-1. Yang, G.-m. Cao, and F.-s. Li, "Underground pressure appearance laws analysis for fully mechanized top coal slice caving on high-dipping thick coal seams," Journal of Coal Science and Engineering, vol. 17, no. 1, pp. 6-11, 2011.

[41] C. Qiao, C. H. Li, X. M. Wei, and Y.-Y. Hu, "Numerical simulation study on the evolution law of mine pressure in deep mining," Arabian Journal of Geosciences, vol. 13, no. 471, 2020.

[42] D. Kong, Y. Lou, S. Zheng, and S. Pu, “The characteristics of roof breaking and the law of ground pressure behavior in fully mechanized top-coal caving face with large mining height," Geotechnical \& Geological Engineering, vol. 39, no. 1, pp. 285-297, 2021.

[43] X. Wu, G. Li, F. Luo, and S. Duan, "A study on the distribution and evolution of mining induced stress under the condition of multiple mining," Geotechnical \& Geological Engineering, vol. 39, no. 2, pp. 1637-1648, 2021.

[44] L. Li, X. He, Y.-q. Chen, Y.-c. Li, C.-h. Shi, and Y.-p. Zhu, "Influence of different propulsion speeds on the characteristics of mine pressure in the fully mechanized caving face during rotary stage," Geotechnical \& Geological Engineering, vol. 37, no. 5, pp. 3937-3947, 2019.

[45] W. Qi, G. Hong, J. Bei et al., "Stability analysis of roadside backfill body at gob-side entry retaining under combined static and dynamic loading," Engineering Failure Analysis, vol. 127, 2021.

[46] Z. Zhang, M. Deng, J. Bai, S. Yan, and X. Yu, "Stability control of gob-side entry retained under the gob with close distance coal seams," International Journal of Mining Science and Technology, vol. 31, no. 2, pp. 321-332, 2021.

[47] C. Wang, M. Hu, X. L. Wang, and Y. Han, "Experimental study on roadway backfill mining of paste-like material," Arabian Journal of Geosciences, vol. 14, no. 611, 2021. 